\title{
Cool, Dry, Nano-scale DIC Patterning of Delicate, Heterogeneous, Non-planar Specimens by Micro-mist Nebulization
}

\author{
S. Shafqat ${ }^{1}$ - J. P. M. Hoefnagels ${ }^{1}$ (i)
}

Received: 19 September 2019 / Accepted: 27 December 2020 / Published online: 26 April 2021

(C) The Author(s) 2021

\begin{abstract}
Background: Application of patterns to enable high-resolution Digital Image Correlation (DIC) at the small scale $(\mu \mathrm{m} / \mathrm{nm})$ is known to be very challenging as techniques developed for the macro- and mesoscale, such as spray painting, cannot be scaled down directly. Moreover, existing nano-patterning techniques all rely on harsh processing steps, based on high temperature, chemicals, physical contact, liquids, and/or high vacuum, that can easily damage fragile, small-scale, freestanding and/or hygro-sensitive specimens, such as MEMS or biological samples. Objective: To present a straightforward, inexpensive technique specially designed for nano-patterning highly delicate specimens for high-resolution DIC. Methods: The technique consists in a well-controlled nebulized micro-mist, containing predominantly no more than one nanoparticle per mist droplet. The micro-mist is subsequently dried, resulting in a flow of individual nanoparticles that are deposited on the specimen surface at near-room temperature. By having single nanoparticles falling on the specimen surface, the notoriously challenging task of controlling nanoparticle-nanoparticle and nanoparticle-surface interactions as a result of the complex droplet drying dynamics, e.g., in drop-casting, is circumvented. Results: High-quality patterns are demonstrated for a number of challenging cases of physically and chemically sensitive specimens with nanoparticles from $1 \mu \mathrm{m}$ down to $50 \mathrm{~nm}$ in diameter. It is shown that the pattern can easily be scaled within (and probably beyond) this range, which is of special interest for micromechanical testing using in-situ microscopic imaging techniques, such as high-magnification optical microscopy, optical profilometry, atomic force microscopy, and scanning electron microscopy, etc. Conclusions: Delicate specimens can conveniently be patterned at near-room temperature $\left(\sim 37^{\circ} \mathrm{C}\right)$, without exposure to chemicals, physical contact or vacuum, while the pattern density and speckle size can be easily tuned.
\end{abstract}

Keywords Digital image correlation $\cdot$ DIC $\cdot$ Speckle pattern $\cdot$ Microscale $\cdot$ Nanoscale $\cdot$ Scanning electron microscopy SEM $\cdot$ Delicate specimens $\cdot$ MEMS $\cdot$ Biological specimens

\section{Introduction}

During the last few decades Digital Image Correlation (DIC) has emerged as a leading technique for measuring shape, displacement and deformation due to its noncontact nature, high (sub-pixel) accuracy [1], applicability with a wide range of imaging setups from cheap webcam base image acquisition [2] to state-of-the-art microscopy techniques, such as High Resolution Transmission Electron Microscope (HRTEM) [3] and applications ranging from health-monitoring of mega-structures [4] down to

\section{J. P. M. Hoefnagels}

J.P.M.Hoefnagels@tue.nl

1 Department of Mechanical Engineering, Eindhoven University of Technology, Eindhoven, 5600MB, The Netherlands atomic scales for studying the deformation fields resulting from electrochemical reactions [3]. Recently, there has been increasing interest in integrating DIC with high resolution microscopy techniques such as Atomic Force Microscopy (AFM) [5, 6] and especially Scanning Electron Microscopy (SEM) [7-10] to understand micromechanical deformation mechanisms as well as performing accurate metrology on micron-sized structures, such as micro-electromechanical systems (MEMS) [11], microelectronics, systems-in-package ( $\mathrm{SiP}$ ), etc. However, one of the most important requirements for the successful application of DIC is the requirement of an (ideally speckle-like) dense, non-continuous pattern on the specimen surface, which the DIC algorithm can effectively track, either globally (in the case of global-DIC [12]) over the whole field of view or locally by dividing the image into smaller subsets (as done in local-DIC [1]) to provide the displacement fields. 
Whereas numerous uncomplicated techniques exist in the literature to create high quality patterns at the meso and macro scales, such as spray painting, achieving a similar pattern quality at the (sub-)micron and nanometer scale remains challenging [13]. A number of very useful smallscale patterning techniques have recently been developed to meet this challenge, each with its own set of advantages and disadvantages. Detailed reviews of these DIC techniques can be found in Refs. [13, 14]. Nevertheless, with all these techniques it remains challenging to pattern fragile smallscale specimens, as these are sensitive to either physical contact, such as (freestanding) MEMS specimens, exposure to heat or chemicals, such as biological or many polymer based-specimens, or high vacuum, such as hygro-sensitive specimens, while such fragile small-scale specimens also typically possess a complex three-dimensional topography. Additionally, multiphase or multi-material specimens, such as a cross-section of a multilayered microelectronics specimen, pose a challenge for achieving a uniform pattern over the whole specimen due to varying surface properties, which strongly affect pattern application at the small scale. In light of these challenges, the existing small-scale patterning techniques exhibit specific advantages and disadvantages, which are briefly discussed next and summarized in Table 1 .

One of the most popular small-scale patterning techniques, developed by Luo et al. [15] and further optimized for DIC afterwards [16-18], involves the growth of a continuous thin film (of $\mathrm{Au}$ ) on the specimen surface by sputter deposition and, subsequently, the 'remodeling' of this thin film in separate islands (speckles) during a thermal treatment. The resulting high density pattern has speckles that are scalable to as small as a few tens of nanometers. However, typically, the technique requires the specimen to be exposed to high temperatures $\left(>100^{\circ} \mathrm{C}\right)$ for a long duration

Table 1 Overview of the most commonly used small-scale DIC patterning techniques from the literature, which are compared here with the specific application in mind of applying a nano-pattern on delicate small-scale, free-standing and/or hygro-sensitive specimens to enable high-resolution DIC on such fragile specimens. The here-proposed micro-mist nebulization technique is given in the bottom row

\begin{tabular}{|c|c|c|c|c|c|}
\hline $\begin{array}{c}\text { DIC } \\
\text { patterning } \\
\text { technique }\end{array}$ & $\begin{array}{c}\text { Pattern quality } \\
\text { (nanometer speckle } \\
\text { size, high density \& } \\
\text { pattern scalability) }\end{array}$ & $\begin{array}{c}\text { Applicability } \\
\text { on physically } \\
\text { \& chemically } \\
\text { fragile specimens }\end{array}$ & $\begin{array}{c}\text { Specimen surface and } \\
\text { topography } \\
\text { independent } \\
\text { processing steps }\end{array}$ & $\begin{array}{c}\text { Surface visibility } \\
\text { (e.g. for simultaneous } \\
\text { EBSD and/or } \\
\text { damage analysis) }\end{array}$ & Cost \\
\hline $\begin{array}{c}\text { (Au) thin film } \\
\text { remodeling } \\
{[15-18]}\end{array}$ & Very good & $\begin{array}{l}\text { High temperature } \\
\left.\qquad>100^{\circ} \mathrm{C}\right) \& \\
\text { high vacuum steps }\end{array}$ & \multirow{2}{*}{$\begin{array}{c}\text { (1) Requires } \\
\text { modifications for } \\
\text { different surfaces } \\
\text { (2) Applicability for } \\
\text { non-flat specimens is } \\
\text { unclear }\end{array}$} & $\begin{array}{l}\text { (1) Damage analysis } \\
\text { possible; (2) Au } \\
\text { islands block EBSD }\end{array}$ & Medium \\
\hline $\begin{array}{c}\text { Ag-Ti-Au-Ti } \\
\text { multi-layer stack } \\
\text { remodeling [19] }\end{array}$ & Very good & $\begin{array}{l}\text { Room temperature, } \\
\text { but liquid immersion } \\
\& \text { high vacuum }\end{array}$ & & \multirow{2}{*}{$\begin{array}{l}\text { (1) Sample surface } \\
\text { not visible } \\
\text { (2) EBSD requires } \\
\text { removal of pattern } \\
\text { (and layers), } \\
\text { e.g., by polishing }\end{array}$} & Medium \\
\hline $\begin{array}{l}\text { (InSn) solder } \\
\text { deposition in island } \\
\text { growth mode }[20]\end{array}$ & $\begin{array}{c}\text { Very good } \\
\text { Surface fully covered } \\
\text { by pattern islands }\end{array}$ & $\begin{array}{l}\text { Room temperature \& } \\
\text { liquid-free, but high- } \\
\text { vacuum process }\end{array}$ & $\begin{array}{l}\text { Approximately } \\
\text { independent of } \\
\text { material surface }\end{array}$ & & Medium \\
\hline $\begin{array}{c}\text { Compressed air } \\
\text { technique } \\
{[21-23]}\end{array}$ & $\begin{array}{l}\text { Challenging to scale } \\
\text { down to sub-micron } \\
\text { sized speckles }\end{array}$ & Good & Good & $\begin{array}{l}\text { (1) Damage analysis } \\
\text { possible; (2) large } \\
\text { particles block EBSD }\end{array}$ & Low \\
\hline $\begin{array}{c}\text { Self-assembled } \\
\text { Au nanoparticles } \\
{[28,30]}\end{array}$ & Very good & $\begin{array}{c}\text { Requires immersion } \\
\text { in (harsh) liquid } \\
\text { solutions }\end{array}$ & $\begin{array}{l}\text { Requires } \\
\text { modifications for } \\
\text { different surfaces }\end{array}$ & $\begin{array}{c}\text { (1) Damage analysis } \\
\text { possible; (2) Au NPs } \\
\text { block EBSD }\end{array}$ & Low \\
\hline $\begin{array}{c}\text { FIB / FEB-assisted } \\
\text { Pt dots deposition } \\
{[32,33]}\end{array}$ & Very good & $\begin{array}{c}\text { FIB can induce } \\
\text { surface damage } \& \\
\text { high-vacuum steps }\end{array}$ & Good & $\begin{array}{c}\text { (1) Damage analysis } \\
\text { possible; (2) Pt dots } \\
\text { block EBSD }\end{array}$ & High \\
\hline $\begin{array}{c}\text { E-beam } \\
\text { lithography } \\
{[13,31,34]}\end{array}$ & Very good & $\begin{array}{l}\text { High-vacuum \& } \\
\text { physical contact } \\
\text { during processing }\end{array}$ & $\begin{array}{l}\text { Requires highly } \\
\text { flat specimens }\end{array}$ & $\begin{array}{l}\text { (1) Damage analysis } \\
\text { possible; (2) EBSD ok } \\
\text { for low-Z thin pattern }\end{array}$ & High \\
\hline $\begin{array}{l}\text { Nano-pattern by } \\
\text { micro-mist nebuli- } \\
\text { zation (this work) }\end{array}$ & Good & Good & Good & Good & Low \\
\hline
\end{tabular}


to help the thin film to separate into small islands (as discussed in Ref. [19]). Whereas the applications for which this technique is being utilized mostly involve bulk metallic specimens that are usually not adversely affected by high temperature or high vacuum, delicate specimens are easily damaged as explained above. Moreover, the speckle size and shape changes with the type of specimen surface, therefore, it is difficult, if not impossible, to achieve a homogeneous pattern on heterogeneous materials. It is also unclear from the literature whether the thin-film remodeling process can be successfully achieved on non-flat specimens.

Recently, a modification to the thin-film remodeling technique was introduced by Montgomery et al. [19] such that the technique can be applied at room temperature. It involves the sputter deposition of a continuous AgTi-Au-Ti multilayered stack on the specimen, which is subsequently immersed in a $\mathrm{NaCl}$ solution for remodeling the top Ag layer into Ag islands (speckles). However, whereas relatively thick specimens can often be immersed in solutions without damage, miniaturized and especially freestanding specimens such as MEMS or biological specimens are often damaged by submersion in any kind of liquid, as well as by the high-vacuum processing step. Additionally, the underlying $\mathrm{Ti}, \mathrm{Au}$ and $\mathrm{Ti}$ layers do not separate into islands, but remain as continuous films on the specimen. Therefore, it depends on the application whether or not the continuous multilayer TiAu-Ti stack does not influence the deformation of the soft/compliant miniature specimens and whether or not the specimen surface deformation is carried one to one to the Ag speckles, i.e. fracture or delamination of one of the layers of the Ti-Au-Ti stack would result in erroneous DIC results. Moreover, the continuous multilayer stack prevents simultaneous study of damage evolution in the underlying specimen or combination of electron backscatter diffraction (EBSD) analysis with DIC, while postmortem EBSD requires removal of the multilayer, e.g., by a polishing step which is typically not possible for delicate, heterogeneous, or non-flat specimens.

Another significant alteration to the sputter-deposition based DIC patterning technique was recently reported by Hoefnagels et al. [20], which also does not require a hightemperature remodeling step nor does it require immersion into a liquid. The technique hinges on sputter deposition of a low-temperature solder (e.g. InSn) at room temperature in 'island growth mode', with the sputter deposition parameters chosen such that islands are directly formed during the growth process. The result is a specimen surface that is (nearly) fully covered by round pattern islands that touch each other. Consequently, very high density, homogeneous DIC patterns, with a feature size that can be tuned from as small as $\sim 10 \mathrm{~nm}$ to $\sim 2 \mu \mathrm{m}$, can be readily achieved with this technique. Moreover, by changing the deposition parameters, it was shown possible to apply multiscale patterns, which allows for multi-scale DIC analysis. In addition, it was shown that the island growth process is approximately independent of the material surface, making it possible to easily apply a homogeneous pattern on heterogeneous specimens. Nevertheless, the high-vacuum required for sputter deposition may still be damaging to delicate, small-scale, or hygro-sensitive specimens. Moreover, the (nearly) full coverage with (thin) pattern islands strongly hampers or even prevents simultaneous damage or EBSD analysis.

A very different type of small-scale patterning technique is the so-called 'Compressed air' technique developed by Jonnalagadda et al., which has been successfully applied on delicate freestanding MEMS specimens [21-23]. The technique passes a dry powder of (micron-sized) particles through a series of filters with the help of compressed air to filter out large aggragates. The filtered Si particles and small aggragates stick to any specimen surface due to electrostatic and van der Waals interactions, making it independent of specimen surface and topography. However, scaling down to sub-micron speckles (particles) constitutes a serious challenge, because the surface energy component of the nanoparticles suspension system increases with decreasing particle size, as the cumulative surface area of the particles in an aggregation of nanoparticles (NPs) strongly increases with decreasing particle size for constant aggregate size [24]. Consequently, NPs have a strong tendency to aggregate to lower the free energy of the suspension system, as discussed in Refs. [25-27]. Moreover, in these particle aggregates, high cohesive forces exist between the particles as the electrostatic and van der Waals forces are dominant at this scale [28]. In other applications, to control the degree of clustering, NPs are typically dispersed in an appropriate solution (e.g. water or ethanol), while the NP surface is modified to promote interaction with the solution over NP-NP interactions [25]. In dried state, however, as in the 'Compressed air' technique, nanoparticles become irreversibly aggregated. As stated in Ref. [29]: "Once submicron particles are aggregated, a large energy barrier persists in the system that promotes the presence of the aggregated masses. The energy barrier to redispersion is greater if the particles have been dried. Therefore, the primary particles must remain dispersed in water and reagglomeration must be prevented by one of the stabilization mechanisms." Therefore, the 'Compressed air' technique is an excellent candidate for delicate, largerscale specimens requiring micron-sized speckles, but not for application of sub-micron speckles.

Another popular small-scale DIC patterning technique utilizing pre-synthesized (nano-)particles called the 'Selfassembled nanoparticles' technique was reported by Kammers et al. [28]. The technique utilizes a dispersion of $\mathrm{Au}$ 
NPs in a solution to prevent aggregation. The specimen surface is functionalized to enhance stiction of the NPs on the specimen surface upon immersion in NP solution. The resulting patterns are of high quality (small speckle sizes and high density), as well as being scalable. However, the immersion into the NP suspension (consisting of aggressive chemicals) can easily damage biological and other delicate specimens. Furthermore, the procedure needs significant modification based on the surface material properties [30, 31], thereby impeding the possibility of a homogeneous pattern on heterogeneous (multiphase or multi-material) specimens.

Finally, other notable small-scale patterning techniques reported in the literature include Focused Ion Beam (FIB) or Focused Electron Beam (FEB) assisted Pt-dot deposition [32, 33] and E-beam lithography [13, 31, 34]. These techniques result in very high quality patterns and the patterning reproducibility is specimen material independent. However, a big drawback is the high equipment cost. Furthermore, FIB assisted deposition can induce surface damage, while FEB assisted deposition is very time consuming, thus only suitable for a very small field of view (e.g. $\left.<5 \times 5 \mu m^{2}\right)[13,14,32]$. E-beam lithography, on the other hand requires a highly flat specimen surface $[14,32]$, which if not originally present would be very difficult to achieve with, e.g. grinding and polishing, without severely damaging fragile specimens. Furthermore, various processing steps, involving physical contact and immersion in solvents, are required for application and removal of a resist layer.

Therefore, this work aims to develop a patterning technique with which it should be possible to pattern delicate specimens. Secondly, it should be a generic technique that can achieve a good pattern in almost all of the possible cases where a small-scale pattern is required, because in most research facilities various specimen types are of interest for analysis, therefore a generic technique would require only a single technique to be mastered. On the other hand, the aim of this work is not to improve upon the very high pattern density of some of the existing small-scale techniques from the literature (discussed above), but rather to develop a patterning technique for delicate specimens which are very difficult or impossible to pattern using those techniques, without causing significant damage. Therefore, the following requirements are set for this new patterning technique:

- Pattern application should be:

$$
\begin{array}{ll}
\text { - } & \text { dry, } \\
\text { - } & \text { at/near room temperature, } \\
\text { - } & \text { contactless. }
\end{array}
$$

- The resulting pattern should be:
- non-continuous, homogeneous distribution of random speckles of high density,

- specimen surface and material independent,

- scalable, without the need for time consuming optimization steps.

- And the patterning setup should be:

$$
\begin{aligned}
& \text { - inexpensive, } \\
& \text { - made of readily available non-specialized } \\
& \text { parts. }
\end{aligned}
$$

\section{Delicate Pattern Application Mechanism}

Herein, we present a patterning technique based on the requirements set above. The methodology uses (commercially available) nanoparticles as the pattern. Similar NPs have been utilized in other patterning techniques [13, 28, $30,35]$ due to a multitude of inherent advantages including, (i) availability in a wide range to particle sizes from a few nanometers to hundreds of micrometers, (ii) a variety of material compositions and surface properties, (iii) easy availability, and (iv) low cost due to numerous applications and mature synthesization technologies. However, the key challenge is to invent an application method to apply a homogeneous, high density pattern with such particles due to their intrinsic tendency to aggregate (as discussed in Ref. [28]). These particles can be homogeneously distributed, e.g., in an aqueous suspension (in which they are typically commercially available) by optimizing parameters such as the $\mathrm{pH}$ level (using $\mathrm{pH}$ buffers) and surface tension (using an appropriate surfactant). However, when this suspension is applied on a specimen and dried as in drop-casting [13], complex droplet dynamics phenomena, highly dependent on the surface properties and other factors, dictate the type of pattern achieved on the specimen [36]. For example, during coffee-stain pattern formation, the liquid inside the droplet is believed to flow to its periphery as the droplet dries and along with it the liquid drags the NPs which come in contact with each other and form uncontrolled aggregates. This is undesirable for a high quality DIC pattern as a homogeneously distributed, random pattern that ideally consists of individual particles is desired. It becomes even more challenging to achieve a homogeneous pattern on a $3 \mathrm{D}$ or multi-material surface. In the 'Self-assembled NPs technique' [28], a solution to this problem is presented, which involves first chemically treating the specimen by silanizing its surface and subsequently dipping the specimen into a bath of freshly synthesized Au NPs. The Au NPs stick to the organosilane molecules at the surface, thereby immobilization the NPs, after which the specimen is rinsed in water. As discussed above, however, since the specimens need to 
be immersed in the NP solution, this technique cannot be applied on the delicate specimens discussed here.

In this work, the NPs diluted in an inert suspension of an ethanol/water mixture are nebulized into an ultrafine mist generated by an ultrasonic nebulizer and carried to the specimen surface by a low velocity inert gas $\left(\mathrm{Ar}, \mathrm{N}_{2}\right.$, or air) flow. In order to inhibit NPs aggregation on the specimen surface, ideally a single NP per droplet (of the mist) is desired, which is controlled by keeping the density of the NPs in the suspension sufficiently low. This way the droplet drying problem of a single large droplet with thousands of NPs in drop-casting leading to aggregation is converted to the case of millions of microdroplets each predominantly containing one (or zero) NP. This makes the patterning technique independent of the specimen surface or material with a rather simple and straightforward process. Furthermore, the microdroplets mist is dried up before it reaches the specimen with the help of a heated passage, which ensures that the solvent evaporates and, thus, only dried particles reach the specimen. This circumvents the possibility of condensation of solvent on the specimen surface and prevents mobility of previously deposited NPs. The choice of the ultrasonic nebulizer comes from the fact that it can provide a narrower micro-droplet distribution in the mist when compared to, e.g., compressed air spray nozzles [37]. Due to the tighter control on the mist droplet size, the ultrasonic nebulizers have gained popularity in some applications as a replacement of compressed gas nozzles, notably in aerosol-based drug delivery devices [38, 39] and spray pyrolysis based thin-film [40-42] and powder/NP synthesis [37, 43, 44]. Furthermore, due the compact nature of the ultrasonic nebulizers, which consists of a piezo transducer connected to a simple driving circuitry, compared to a nozzle attached to a compressor or pump, the ultrasonic nebulizers have gained popularity in portable commercial applications, such as aerosolbased drug delivery devices, household humidifiers, etc. Consequently, a wide range of nebulizer kits are available from a number of vendors at a low price. For instance, the nebulizer kit (TKD nb-59s-09s-0) used in the setup described here costs approximately $\$ 60$.

In the proceeding section, details of the pattering setup are presented for reproduction. Subsequently, in the results section high density patterns utilizing NPs of $50 \mathrm{~nm}$, $300 \mathrm{~nm}, 500 \mathrm{~nm}$ and $1 \mu \mathrm{m}$ size on various types of delicate specimens are shown to demonstrate the feasibly of patterning technique.

\section{Setup Design}

The design of the setup developed for patterning is described here in detail for the purposes of reproduction.
It was intended to keep the design of the setup simple for ease of reproduction by fellow researchers. Therefore, even when specialized components were available, inexpensive and more readily available alternatives were used instead, such that the total cost of the setup was kept well below $\$ 1000$.

A schematic drawing and photograph of the setup with all the main components is shown, respectively, in Figs. 1 and 2. The setup essentially consists of three main sets of parts. The first set marked by lettering A in Fig. 1, consists of the main nebulizer tube [A1] and associated parts where the NP suspension [A4] is kept at low temperature and nebulized with the help of a piezoelectric ultrasonic nebulizer [A2]. The next set of parts marked by lettering $\mathrm{B}$ in Fig. 1, generates a flow of clean air with a controlled flow rate and this airflow carries the nebulized droplets of the suspension toward the specimen out of nebulizer tube. Subsequently, the nebulized mist is passed through a passage (marked by lettering $\mathrm{C}$ ), part of which is heated to completely vaporize the liquid component of the mist, resulting in dried NPs. Finally, the NPs are deposited on the specimen in a turbulent flow [D4].

The nebulizer tube [A1] is machined from aluminium, with a relatively long length, such that there is enough height available for the jet resulting in micro-droplet mist to form freely. The length of the tube (from the top of the piezoelectric ultrasonic nebulizer to the top of the tube) is chosen to be $17 \mathrm{~cm}$, while the inner diameter of the nebulizer tube is $3.3 \mathrm{~cm}$. The 3D CAD files detailing the design of the nebulizer tube and other machined parts are provided in the Supplementary Material section in universal CAD format. An air inlet hole at the top (in which the syringe filter [B3] fits) was drilled at a slanting downwards angle $\left(\sim 30^{\circ}\right.$ with respect to the axis along the length of the tube) to allow a flow of air to be injected into the nebulization tube that lifts the NPs containing mist out of the tube. A piezo actuator [A2] is fitted at the bottom of the nebulizer tube through a simple adapter plate, while a seal cut out from a $0.5 \mathrm{~mm}$ Teflon sheet is used as a seal between the adapter plate and the bottom of the nebulizer tube. Apart from a few Teflon components the setup is completely free from polymers, restricting the choice of materials to metals and glass, since any polymers leaching or dissolving into the solution would end up as hydrocarbon residue on the specimen. Teflon is nearly chemically inert, so where the use of polymers was unavoidable, Teflon based components were used. A commercially acquired ultrasonic nebulizer (TDK nb-59S-09S) was used here. The transducer has an operating frequency of 1600-1720 $\mathrm{kHz}$, which results in a mean droplet size of the nebulized mist of $\sim 2 \mu \mathrm{m}$, using the analytical equation in Ref. [45] based on values of the density and surface tension for a mixture of 25 volume/volume $\%$ of ethanol in DI water 
Fig. 1 Schematic drawing of the here-proposed patterning setup

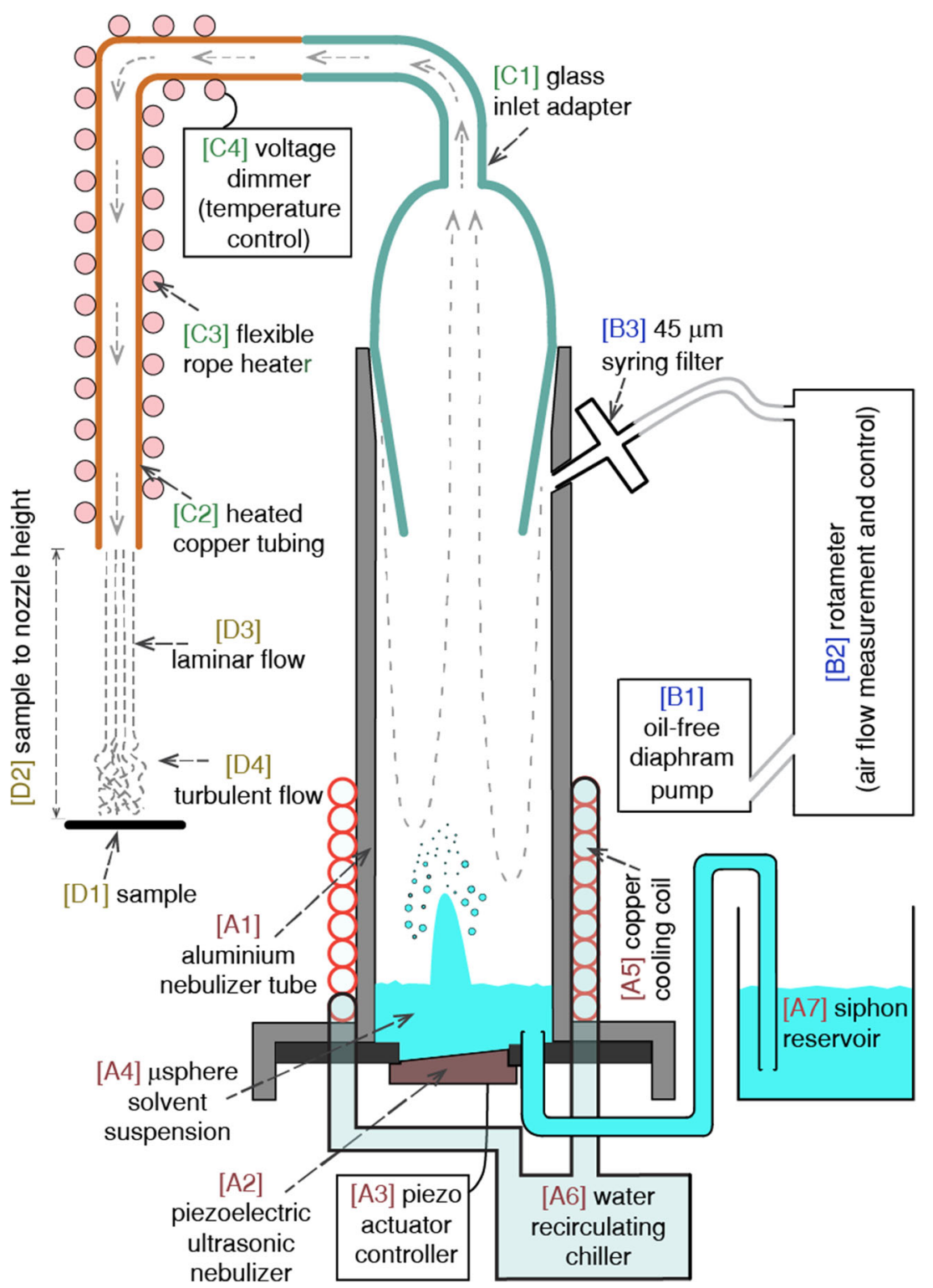

obtained from Ref [46]. The nebulizer kit is provided with the driving electronic circuitry, therefore, the transducer only needs to be installed onto the bottom of the nebulizer tube for operation. The electrical circuitry, more specifically a specific power-transistor on the circuit, can heat up to high temperatures over time, therefore, it is advised to attach a heat-sink to the power-transistor and keep it in a well-ventilated location to avoid an electrical burnout. Ultrasonic nebulizers operate most efficiently at a specified liquid column height above the transducer. For the specific transducer used here, the optimum liquid column height is found to be $13 \mathrm{~mm}$ above the transducer surface for the 25 $\mathrm{vol} / \mathrm{vol} \%$ mixture of ethanol in DI water. The mist output shows a rather broad optimum as a function of the liquid column height, which can be monitored visually through the glass inlet adapter (Fig. 1 [C1]). This optimum liquid column level value is expected to be different only if another type of solvent is used. The nebulizer tube can contain only a small volume of liquid, therefore, to maintain a constant liquid level above the transducer of approximately $13 \mathrm{~mm}$ for a few hours of deposition, a reservoir is connected to the nebulizer tube via a siphon (Fig. 1 [A7]). At the base of the nebulizer tube, a u-shaped bent tube from soft copper tube (O.D. $8 \mathrm{~mm}$ ) is attached, which in turn is attached by means of Teflon tubing to the tubing end residing at the bottom of the reservoir. Alternatively, a float switch or level sensor placed in the nebulizer tube and connected to a valve between the nebulizer tube and the reservoir can be utilized to maintain the liquid level at a constant height. The temperature of the NP-suspension inside the nebulizer tube can reach up to $50^{\circ} \mathrm{C}$, within a few minutes of operation, due to the high vibrational energy generated by the actuator. 
Fig. 2 Photograph of the here-proposed patterning setup with its key components, including: (1) nebulizer tube, (2) copper cooling coils, (3) Teflon tubing connecting the nebulizer tube to the siphon reservoir beaker (4), (5) in-line pump for pumping water from the fan-cooled radiator (not shown here) to the copper cooling coil, (6) rotameter for controlling air inflow to the nebulizer tube passing through a $45 \mu \mathrm{m}$ pore size syringe filter (7), (8) rope heater wound around the L-shaped heated copper passage and (9) lab-jack (on which the specimen resides) for setting the specimen to nozzle distance

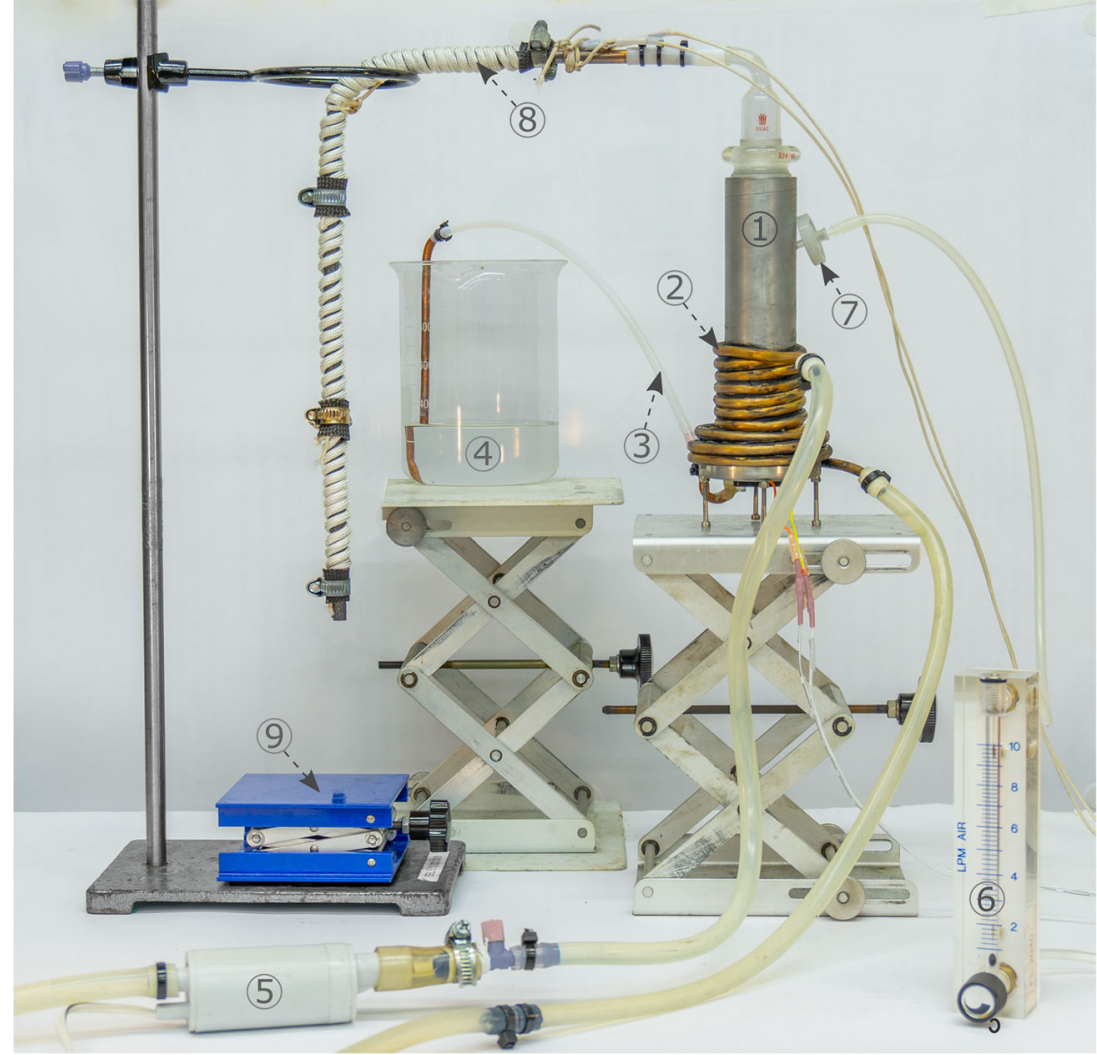

While a higher liquid temperature can be beneficial for achieving a higher micro-mist output from the nebulizer, here it is undesirable as at higher temperature more energy is available to the NPs resulting in particle aggregation already in the suspension. Depending on their constituent material, NPs should be kept at a specified temperature to ensure their stability in liquid suspension in order to avoid aggregation. Many NP suspensions, e.g., silica NPs in DI water or ethanol are stable around room temperature, while certain particle suspension such as Au NPs in DI water typically require refrigeration for stability. Therefore, the nebulizer tube is cooled to stay close to room temperature for the choice of particles used here. The easiest solution would be to attach cooling fins around the nebulizer tube. However, the cooling fins were not found to be efficient enough without a strong air flow from a fan, while a strong air flow in the vicinity of the output nozzle is disruptive for the flow of the dried NPs approching the specimen surface. Therefore, liquid cooling was used here instead and a cooling coil was made by bending commercially available 8-mm soft copper tubing around the nebulizer tube (Fig. 1 [A5]). The water was recirculated through the cooling coils and a fan-cooled radiator (Enermax LiqFusion) using a simple in-line pump (Comet 1005.02.00). Using this assembly, the temperature of the suspension inside the nebulizer tube could be kept to $30{ }^{\circ} \mathrm{C}$, which was enough to prevent temperature-induced NP aggregation.
For suspensions requiring refrigeration temperatures, the cooling coil can be attached to a compressor based liquid chiller, e.g., using a recirculating chiller (Caron 2050W) a temperature of $4{ }^{\circ} \mathrm{C}$ was easily reached inside the nebulizer tube.

The transport gas (air) to push the NP mist out of the nebulizer tube and onto the specimen is obtained from a miniature diaphragm pump (VWR VP 86) marked as [B1] in Fig. 1. It is important to use an oil free pump to avoid any contamination of the setup and the specimen. Alternatively, other inert gases such as $N_{2}$ or Ar, typically available in laboratories can be utilized here. However, it is important to take into account the flow rate conversion factors to recreate the same results for different gases. The flow rate is measured and controlled with the help of a rotameter (Omega FL-2013) (Fig. 1 [B2]) for flows in the range of 0.4 to 5 litres per minute (LPM). A disposable syringe filter (PTFE membrane, VWR 514-0067) with a pore size of $45 \mu \mathrm{m}$ (Fig. 1 [B3]) is subsequently used to filter out any residue such as dust before the air flow is injected into the nebulizer tube. The airflow drags the nebulized mist containing the NPs out of the nebulizer tube upwards towards the specimen. The nebulized mist is subsequently heated to vaporize the solution in each micro-mist droplet such that dry particles arrive at the specimen surface. The first part of this passage way is a 24/40 joint, glass inlet adapter (Fig. 1 [C1]) with a $90^{\circ}$ bend (VWR 201-0348). 
The inlet adapter fits into the nebulizer tube with the help of a bushing adapter with 24/40 inner female joint and 34/45 outer male joint (Laboy HMA012011). The tube connector end of the inlet adapter is attached to a soft 45-mm long copper tube bent into an L shape (Fig. 1 [C2]). A 400 Watt flexible rope heater (Omega FGR-080/240V) with a total length of 8 feet is wrapped around the copper tubing [C3]. Typically such a heater is attached to a temperature controller, however, for ease of design, a simple AC dimmer (IVT DR-2000 Hand-Dimmer), offering PWM-based power (temperature) control, was used instead, see Fig. 1 [C4].

\section{Patterning Methodology}

To start the procedure, the setup is rinsed with ethanol to remove any dried and aggregated particles from previous depositions. Next, a low-concentration suspension of the NPs in a volatile solvent needs to be prepared, because the particles typically come in a highly concentrated suspension (typically DI water) and thus need to be diluted. The exact concentration depends on the particle size and initial solution concentration. A too low particle concentration in the suspension results in an excessively long deposition time, while a too high concentration leads to an aggregated pattern, as a result of NPs coming in contact with each other in the suspension and/or the formation of nebulized droplets containing multiple NPs. Here, the concentration of the solution is optimized by starting with a low concentration and increasing until the first, larger, spherical aggregate can be seen, where the spherical shape is a clear indicator that the aggregate was formed before touching the specimen. Before this point, it is assumed that almost all micro-mist droplets carry only one (or zero) particle.

The choice of the liquid in the suspension depends on a number of factors. Firstly, the liquid should be volatile at relatively low temperatures such that in the micromist the liquid can be easily evaporated. Secondly, it is desired that the liquid possesses a low surface tension for higher dispersibility of the NPs in the suspension and thus less aggregation. Considering these factors alcohols would be an ideal choice, however, in our experience it led to a 'hydrocarbon'-like residue accumulating over the specimen surface. We hypothesize that this might be resulting from less volatile hydrocarbons being dissolved in the suspension from the setup (although care was taken not to have any dissolvable materials in the setup) or, alternatively, the hydrocarbon residue from the ambient air being dissolved in the air stream. DI water is a better option to avoid hydrocarbon solubility, however, it has a higher surface tension leading to a more aggregated pattern and a higher boiling point. A solution was found by using mixture of ethanol and water, since addition of $25 \mathrm{vol} / \mathrm{vol} \%$ ethanol significantly reduces the surface tension (at room temperature and atmospheric pressure) of DI water from $72.1 \times 10^{-3} \mathrm{Nm}^{-1}$ (for pure DI water) to $\sim 38.2 \times 10^{-3}$ $\mathrm{Nm}^{-1}$, while the surface tension of pure ethanol is only a bit lower at $21.8 \times 10^{-3} \mathrm{Nm}^{-1}$ [46]. The $25 \mathrm{vol} / \mathrm{vol} \%$ ethanolwater mixture was found to result in a good dispersibility of NPs in the suspension and significantly reduced aggregation on the specimen, while a hydrocarbon residue is prevented. It should be noted that laboratory grade DI water should be used. In our experience, significant microplastic residue consisting of microspheres ranging from a few $\mathrm{nm}$ to hundreds of $\mu \mathrm{m}$ were found in several sources of DI water, including DI water from laboratory filtration stations, as found by drop-casting and analysis in SEM. The DI water used here was obtained from VWR with MDL number: MFCD00011332 and CAS number: 7732-18-5.

A wide variety of NPs of different material compositions are commercially available, including metals $(\mathrm{Au}, \mathrm{Ag}, \mathrm{Cu}$, etc.) ceramics and polymers, with silica, and polystyrene particles being most widely available. Furthermore, dyed, fluorescent and surface functionalized NPs are also readily available. In combination with the choice of the ethanol/water solvent, silica and polystyrene NPs were used. Both types of NPs are offered, at low price, by various commercial suppliers in a range of particle sizes and in forms that can be stably re-dispersed in the ethanol/water solvent without the need for a surfactant (e.g. by employing an electrostatic stabilization mechanism), which would otherwise typically result in a non-volatile residue on the specimen surface.

Typically, a solution of $200 \mathrm{ml}$ was used and during an hour of deposition approximately $20 \mathrm{ml}$ of the solution would be consumed. As suggested by the NP manufacturer, prior to use, the suspension was sonicated for around 30 minutes in a bath sonicator to break any particle aggregates and to distribute the particles homogeneously in the suspension. During sonication over tens of minutes the temperature of the liquid can increase up to $50^{\circ} \mathrm{C}$, therefore, to avoid elevated temperature induced aggregation, it is important to control the bath temperature of the sonicator. Finally, the sonicated solution is added to the nebulizer tube and a siphon is established between the setup and the reservoir, by first completely filling up the nebulizer tube with the suspension and then lifting it up till the liquid passes to the reservoir beaker and all the air is forced out. The height of the liquid in the nebulizer tube is set to the optimum height of $13 \mathrm{~mm}$ by adjusting the lab jack below the siphon reservoir beaker (Fig. 2 (4)).

Subsequently, the nozzle to specimen distance is set by adjusting the height of the lab jack beneath the specimen (Fig. 2 (9)). This distance, together with the suspension concentration is the most important parameter to obtain good pattern quality. One may intuitively assume that it 
would be best if the specimen is kept as close as possible to the nozzle to 'catch' all the particles and thus obtain a highdensity pattern. However, in this configuration numerous planar particle aggregates are typically noticed, as seen in Fig. 11 shown in Appendix. Such planar aggregates typically points to the case that the aggregation is happening on the specimen itself, likely due to an enhanced particle mobility at specimen surface induced by the forced airflow. Planar aggregates, especially those in long chains could break under localized deformation or partially slide on the surface to comply with the local deformation, thus resulting in erroneous results, therefore, they should be avoided. Another observation was made that close to the nozzle the flow appears to be laminar, whereas further away from the nozzle the flow becomes turbulent (as was visualized in Fig. 10 in Appendix) and, importantly, it was observed that a more homogeneous NP pattern is achieved when the specimen is kept in the turbulent region, i.e., at a sufficient distance from the nozzle. Therefore, it is important to adjust the specimen-to-nozzle distance ([D2]) such that the specimen is positioned in the turbulent regime, as schematically shown in Fig. 1. Based on the relationship of the Reynolds number of a free-jet flow [47], the flow can be made turbulent by either increasing the nozzle diameter, the flow rate (velocity), or the specimen-to-nozzle distance. Increasing the diameter would increase deposition time, since the particles would be spread over larger area on the specimen. Increasing the flow rate is beneficial to a certain degree since it also brings more droplets and thus particles from the nebulizer tube to the specimen, thus decreasing deposition time. However, beyond a certain flow rate, an additional increase becomes detrimental, as a high flow rate can also carry very large nebulized droplets, resulting in large spherical aggregates. We found good results for a flow rate of around 3 LPM of air in combination with a specimento-nozzle distance of $7.5 \mathrm{~cm}$ and a nozzle width and inner diameter of $6 \mathrm{~mm}$. It is suggested to calibrate the specimento-nozzle distance while the heating is turned off since then the flow of nebulized mixture can still be visualized as a faint translucent flow, as shown in Fig. 10 in Appendix. This way of visualization of the flow pattern is important as it allows to determine the optimal specimen location, which is approximately in the middle of the turbulent regime. If, however, the specimen is kept at the end of the turbulent regime or even further away from the nozzle almost no particles land on the specimen surface, which may give the impression that the technique is not working. Likewise, when the specimen is placed besides the flow axis (i.e. more than $\sim 15 \mathrm{~mm}$ away from the axis for the settings used) very few particles land on the specimen surface also giving the impression that the technique is ineffective or not working at all.
After $\sim 15$ minutes of operation, a steady-state temperature of $\sim 200^{\circ} \mathrm{C}$ (measured with a thermocouple) is reached at $75 \%$ input power. It should be noted that while the temperature of the outflow at the nozzle is considerably quite high, by the time it reaches the specimen, it drops to $\sim 37$ ${ }^{\circ} \mathrm{C}$, which was confirmed in many experiments. Finally, it is important to note that at any moment (e.g., at intermittent intervals) the specimen can be taken out of the patterning setup and examined under a microscope to check if the desired density has been achieved and, if not, the specimen can be placed back again under the setup to increase the density, a process that is demonstrated in the next chapter.

As mentioned above, a specimen-to-nozzle distance of $7.5 \mathrm{~cm}$ was found to be optimum for deposition at a flow rate of 3 LPM. Therefore, these values were used for all test cases described in the next section while the particle suspension concentration (in a $25 \mathrm{vol} / \mathrm{vol} \%$ ethanolDI water mixture) was optimized for each size of the tested NPs, as reported below. All NPs were obtained from Micromod Partikeltechnologie $\mathrm{GmbH}$. It was found that for very small sizes, such as the $50 \mathrm{~nm}$ particles, NP aggregation was the determining factor for achieving a good pattern and silica particles provided the best results in terms of an unaggregated pattern. At larger particle sizes, such as the $1 \mu \mathrm{m}$ NP diameter, while the silica particles provided a high quality unaggregated pattern, the density could not be increased with longer deposition time beyond a certain pattern density. On the other hand, the polystyrene $(1 \mu \mathrm{m})$ NPs provided a high quality pattern as well, while the density did continue to increase with longer deposition time, the reason for which remains unknown to the authors. Therefore, at the high end of the spectrum, i.e., NP diameters at or above $1 \mu \mathrm{m}$, polystyrene NPs seem to provide the best results in terms of reaching a high density, while at the low end of the spectrum, i.e., around $50 \mathrm{~nm}$ diameter, silica NPs provide a higher quality pattern. In the medium particle diameter range, e.g., at $500 \mathrm{~nm}$, both silica and polystyrene NPs seem to result in a similar type of pattern and can be used interchangeably. Table 2 lists all the NPs tested here with the corresponding parameters that were employed for patterning.

Please note that the NP manufactures warn that prolonged inhalation of (silica) NPs can be hazardous, therefore, it is important to operate the setup in a fume hood with the lid closed.

\section{Experiments: Pattern Test Cases}

To show the applicability of the patterning technique, a wide range of patterning examples are given here, including patterns deposited with a range of particle sizes, specimens 
with different surface characteristics, and various types of delicate specimens.

\section{$500 \mathrm{~nm}, 50 \mathrm{~nm}$ and $1000 \mathrm{~nm}$ NPs Patterns on Polished Steel}

The first example is a pattern of $500 \mathrm{~nm}$ silica particles (with a plain, non-functionalized surface) deposited on a flat steel specimen, which was cut into a $20 \times 20 \mathrm{~mm}^{2}$ square piece from a commercially acquired (Metaalwinkel B.V.), 2-mm thick, 316 stainless steel plate and, subsequently, mirror polished. The suspension of nanoparticles, which was provided by the manufacturer in a solution of DI water without surfactant at a concentration of $50 \mathrm{mg} / \mathrm{ml}$, was diluted into a ratio of 1:4000. The specimen has been patterned for a total duration of 110 minutes, in a number of deposition time intervals, after each of which the nanopattern was imaged by optical microscopy. The final pattern is shown in Fig. 3a, in which each particle has been color-coded corresponding to the deposition time interval in which the particle has been deposited, thereby clearly demonstrating the continuous increase in pattern density with increasing deposition time. This also highlights an advantage of this technique over other pattering techniques, i.e., that the pattern density can be monitored during the deposition process and increased additively to the desired level. As it can be seen in Fig. 3b and c, many particles have landed next to previously deposited particles on the specimen without the occurence of aggregation. Only a few spherical aggregates can be seen in Fig. 3, which are unavoidable due to variability in the size of nebulized droplets thus inevitably resulting in a few large droplets containing multiple NPs. But the vast majority of droplets contained one (or zero) nanoparticle.

For many high-resolution DIC applications, such as the quantification of sub-grain strain fields, obtaining a DIC pattern with speckle sizes below $100 \mathrm{~nm}$ is of special interest. Therefore, a DIC pattern with $50 \mathrm{~nm}$ plain silica NPs was applied on a mirror-polished steel specimen (similar to the one described above) for $210 \mathrm{mins}$, as shown in Fig. 4. The specimen was imaged by scanning electron microscopy (SEM). It can be seen that a homogeneous high-density pattern has been deposited. To this end, the original NP suspension was diluted into a ratio of 1:40000.
Fig. 3 Color-coded optical microscopy image of a polished steel specimen deposited with $500 \mathrm{~nm}$ silica nanoparticles. The insets show the magnified region marked by the dashed rectangle, with (b) the color-coded image and (c) the original dark field image. Images were taken at four time intervals and the colors represent the particles deposited in each of the four time intervals. The images were acquired using an Zeiss Axioplan 2 reflective light microscope with a 50x objective lens in dark field contrast mode
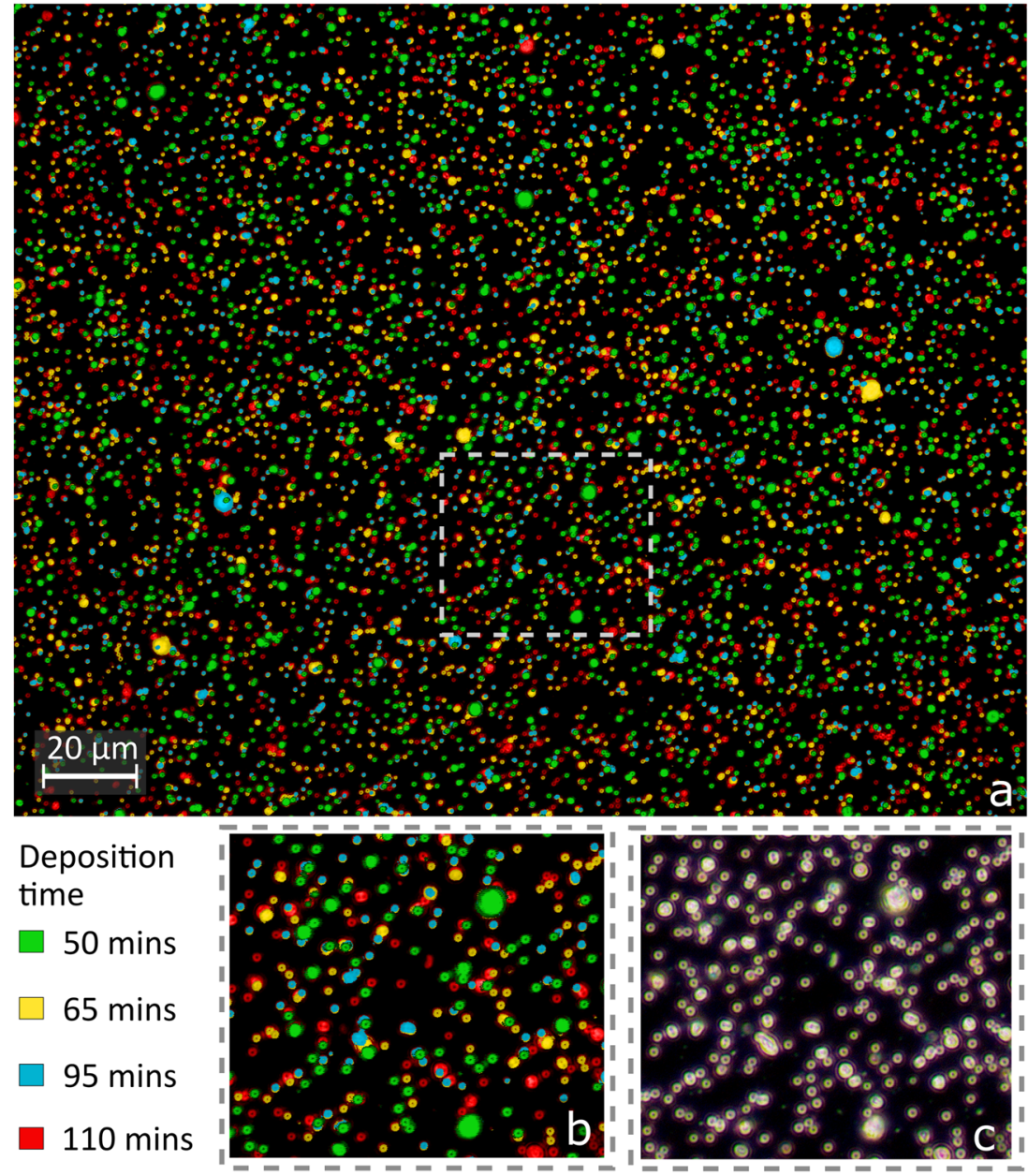


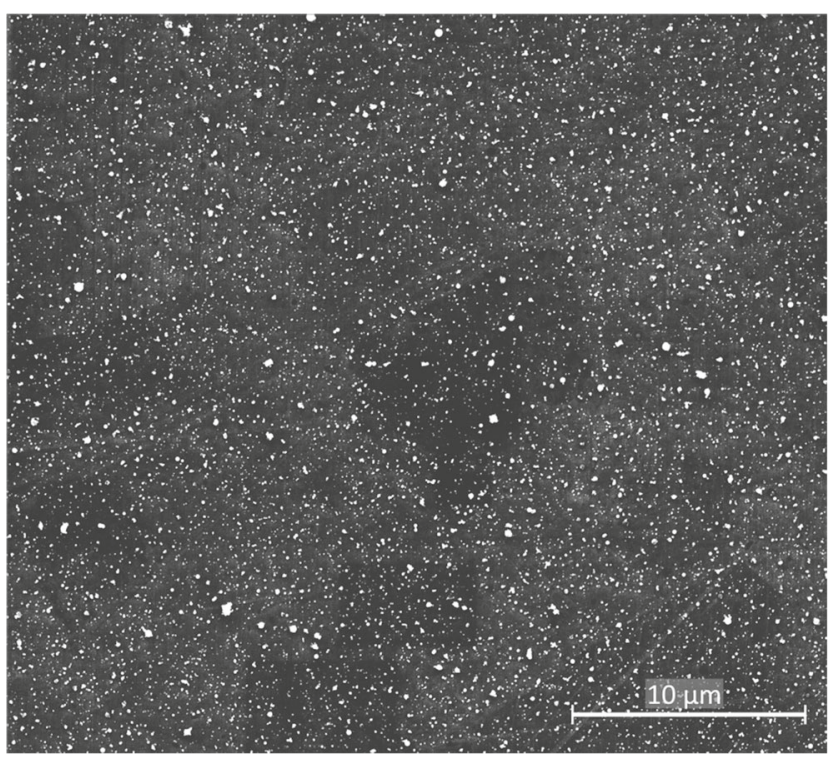

Fig. 4 SEM image of $50 \mathrm{~nm}$ silica NPs deposited on a polished steel specimen. The SEM image was captured using a FEI Quanta 600 FEG SEM in secondary electron contrast mode, under high vacumm, with an acceleration voltage of $8.5 \mathrm{kV}$, a spot size of 3 , and a working distance of $10 \mathrm{~mm}$

Although not tested, it should be possible to deposit smaller sized NPs down to few $\mathrm{nm}$, which are still commercially available, however, the source solution would need to be diluted further, because the chance of finding more than one NP in a nebulized droplet increases for decreasing NP size, for the same concentration.

Finally, to explore the upper limit of the particle size that can still be applied, $1 \mu m$ polystyrene NPs have been deposited on a mirror-polished steel (described above) specimen, as shown in the low-vacuum SEM image in Fig. 5. The original suspension was diluted by a ratio of 1:100 and the specimen was deposited for 480 mins. As mentioned earlier, the average droplet size of the mist for the nebulizer used in the setup is estimated to be $\sim 2 \mu \mathrm{m}$. Therefore, it becomes difficult to deposit particles larger than $2 \mu \mathrm{m}$.

\section{LED Cross-Section: Varying Material Composition Specimen}

A major challenge in small-scale pattering is the surface dependent adherence of the speckles onto the specimen surface. While at larger scales, techniques such as airbrushing can be utilized to obtain a reproducible pattern on specimens with almost any material composition, at the $\mu \mathrm{m} / \mathrm{nm}$ scales, the adherence of the patterning material

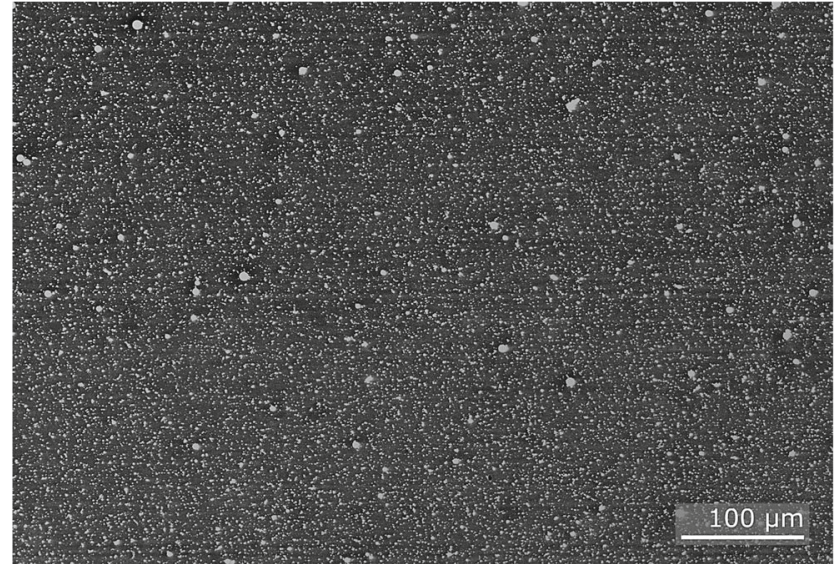

Fig. $51 \mu m$ polystyrene NPs deposited on a polished steel specimen deposited for $8 \mathrm{hrs}$. The SEM image was captured using a FEI Quanta 600 FEG SEM, in secondary electron contrast mode, in low-vacuum mode (at $1.3 \mathrm{mbar}$ ), at an acceleration voltage of $20 \mathrm{kV}$, spot size of 3 , and working distance of $10 \mathrm{~mm}$

on the specimen is highly dependent on the physical and chemical interactions of the patterning materials with the specimen surface material. For instance, the 'selfassembled nanoparticles' technique [30, 31] and the 'thinfilm remodeling' technique [16] both require process modifications or parameter optimization based on the specimen material. Optimization to a specific specimen surface becomes even more complicated when a specimen is composed of multiple materials/phases, such as the cross-section of a light emitting diode (LED), as seen in Fig. 6, which is composed of an epoxy lens, a ceramic (AlN) substrate, and metal $(\mathrm{Cu})$ electrodes on a polymer printed circuit board (PCB). For such a specimen DIC can provide useful insight in, e.g., thermo-mechanical induced shear strains at the interfaces potentially causing decohesion induced failure. For this specimen, application of a suitable pattern over the whole specimen is not only challenging due to the highly heterogeneous surface properties, but also due to the sensitivity to chemical reactions (e.g., corrosion of $\mathrm{Cu}$ in DI water) and sensitivity to high temperatures (e.g., of the epoxy lens and polymer PCB). The specimen surface in Fig. 6 was prepared by grinding and polishing the LED specimen, after it was cold mounted in a two-part epoxy (EpoFix by Struers). The grinding was performed using SiC paper with grit size 120,320, 800, 1200 and 2000 with water and subsequently polished with MD-Dac polishing cloth with $3 \mu m$ diamond spray and finally with MD-Nap with 1 $\mu m$ diamond spray.

The patterning technique described here can be very convenient for such specimens, since only dry NPs come 
Fig. 6 Nanoparticle pattern with $200 \mathrm{~nm}$ polystyrene particles applied to a LED cross-section, with (a) a low-magnification backscatter electron contrast image of the LED cross-section, and (b,c,d,e) secondary electron contrast images of (b) the $\mathrm{Cu}$ electrode, (c) the aluminumnitride substrate, $(\mathbf{d})$ the polymer $\mathrm{PCB}$, and (e) the epoxy lens, where subfigures (b)-(e) were taken at the same magnification. All images were captured using a FEI Quanta 600 FEG SEM operated in low-vacuum mode (1.3 mbar), at an acceleration voltage of $20 \mathrm{kv}$, spot size of 3 , and working distance of $10 \mathrm{~mm}$

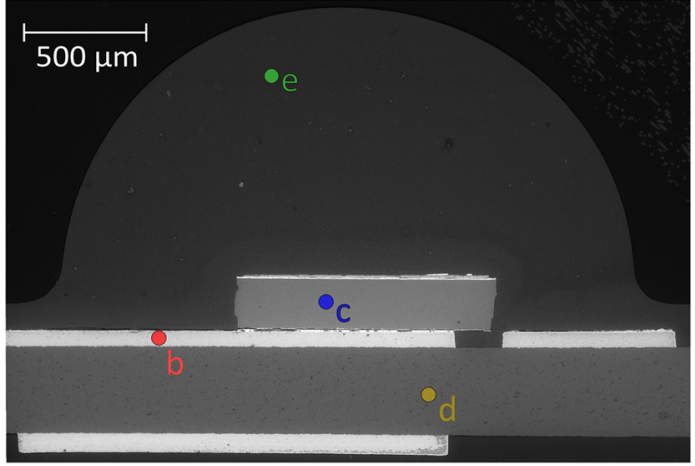

(a) LED polished cross-section

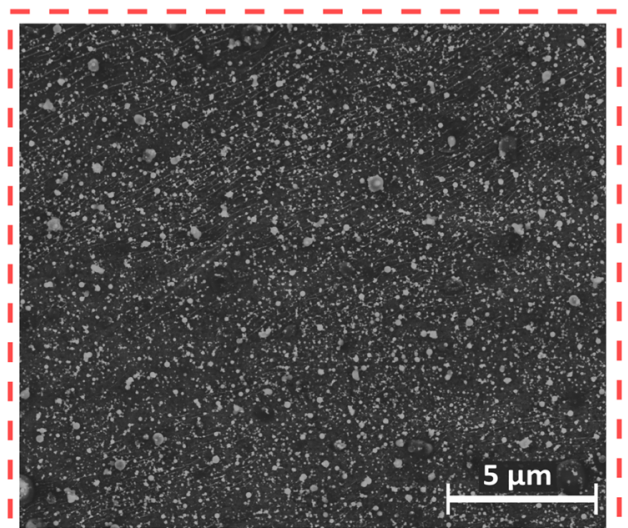

(b) Cu electrode

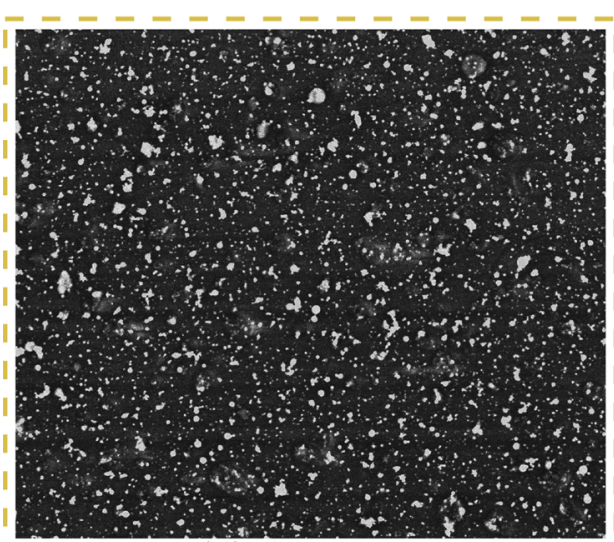

(d) plastic PCB

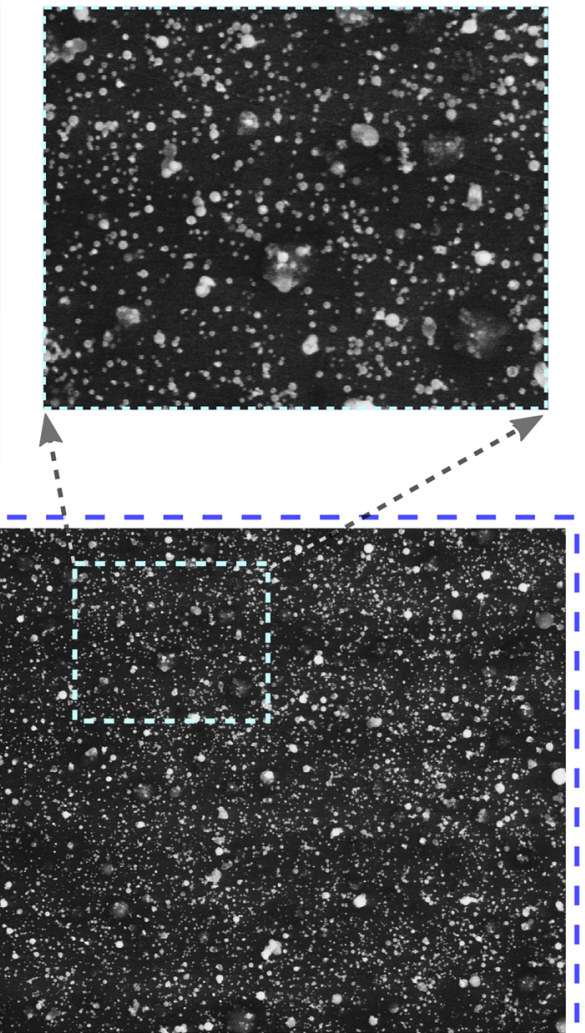

(c) aluminium nitride substrate

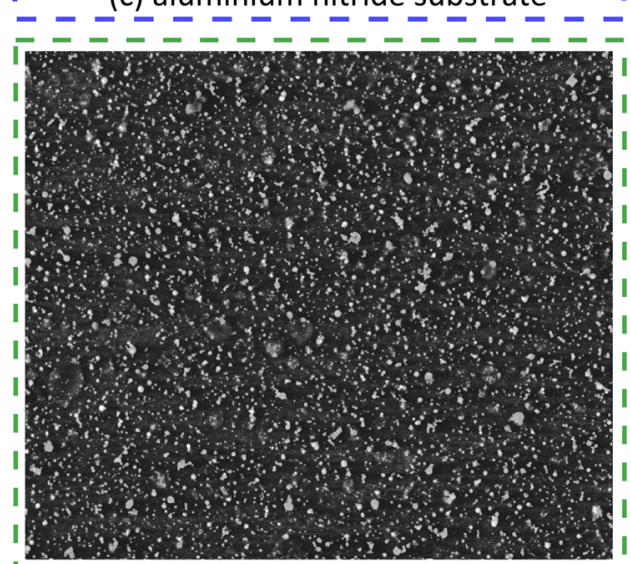

(e) Epoxy lens in contact with the specimen and adhere to the surface due to physical interactions, including van der Waals forces. Importantly, it was consistently observed that all the deposited particles, ranging from $50 \mathrm{~nm}$ to $1 \mathrm{\mu m}$ once deposited cannot be blown off the surface even with pressurized air. In contrast, when a droplet of water or ethanol is added to the patterned surface, the NPs disperse in the liquid and subsequently rearrange on the surface as the liquid dries, leading to, e.g., the so-called 'coffee-staining' effect [36].

The LED specimen shown in Fig. 6 was patterned using $200 \mathrm{~nm}$ plain polystyrene NPs and the suspension was diluted with a ratio of 1:6000 and the specimen was patterned for 960 mins. Importantly, the different material composition areas show a very similar high pattern quality and density. Therefore, this example nicely demonstrates 
the feasibility of the micro-mist nebulization technique for application of a homogeneous nanopattern on highly heterogenous specimens.

\section{Synthetic Hydrogel Fiber for Biological Applications: (Chemically Sensitive Specimen with Topography)}

Applications of DIC on biological specimens typically involves dealing with specimens that are highly delicate in terms of interactions with chemicals. Moreover, such specimens are typically non-planar or highly textured, and planarization can negatively affect their structure and properties that are to be investigated using DIC. Additionally, biological specimens can be easily damaged under (high) vacuum conditions by loss of moisture and even moderately high temperatures. Therefore, patterning such specimens requires a dry technique, where the specimen does not come in contact with any chemical, even water, and is not subjected to any vacuum. Moreover, the patterning needs to be isotropic over the non-uniform three-dimensional topography.

An example of such a specimen is a synthetic hydrogel fiber used in 3D printing of bioreactive scaffolds that can be employed for in-situ tissue regeneration [48]. The hygroexpansion of the hydrogel material is used as a means for dynamic actuation of the overall structure [49, 50]. Therefore, quantifying the hygroexpansive swelling behavior of such materials, e.g., using Digital Height Correlation (DHC) together with surface profilometry or AFM imaging is of special interest [51-54].

The cylindrical hydrogel fiber specimen, shown in Fig. $7 \mathrm{a}$, was patterned using $500 \mathrm{~nm}$ plain silica particles for 360 mins. Details of the exact material composition of the hydrogel fiber are provided in Ref. [48]. The as-
Fig. 7 Pattern application to an ultra-delicate hydrogel fiber. (a1) Un-patterned initial fiber surface. (a2) Topographical profile of the fiber highlighting the approximately cylindrical shape of the fiber. (b1) The same region as (a1) after patterning for $360 \mathrm{~min}$ with damage visible on the surface due to previous electron beam exposure. (c1) An adjacent region of the fiber after 360 mins of patterning, not previously exposed to the electron beam, with no visible damage, which demonstrates that the damage in subfigure (b1) was not caused by the patterning operation but by the SEM image taken prior to patterning. (b2 and c2) The magnified views on the right show the same density of the pattern at the steep side surface of the fiber. (d) A fiber from the same material severely damaged after patterning the same suspension of NPs using an airbrush, even though the most delicate airbrush setting were used, which shows that delicate, biological specimens are often seriously damaged by airbrush pattern application. Note that (a)-(d) have been imaged at the same magnification using a FEI Quanta 600 FEG SEM in low-vacuum mode at 1 mbar, acceleration voltage of $8.5 \mathrm{kV}$, spot size of 3 , and a working distance of $10 \mathrm{~mm}$
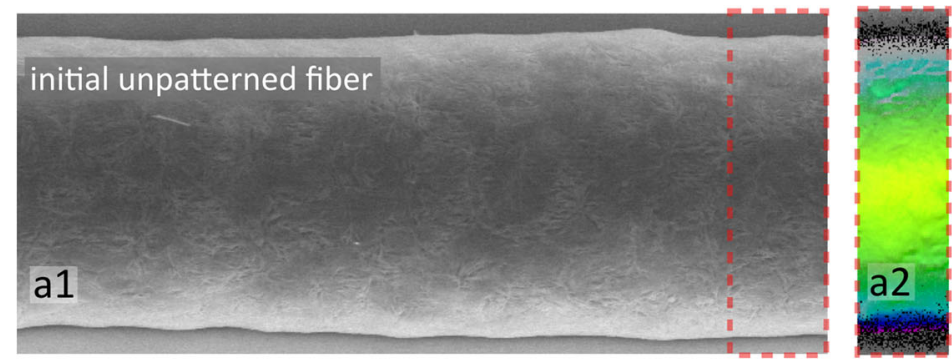

27.0
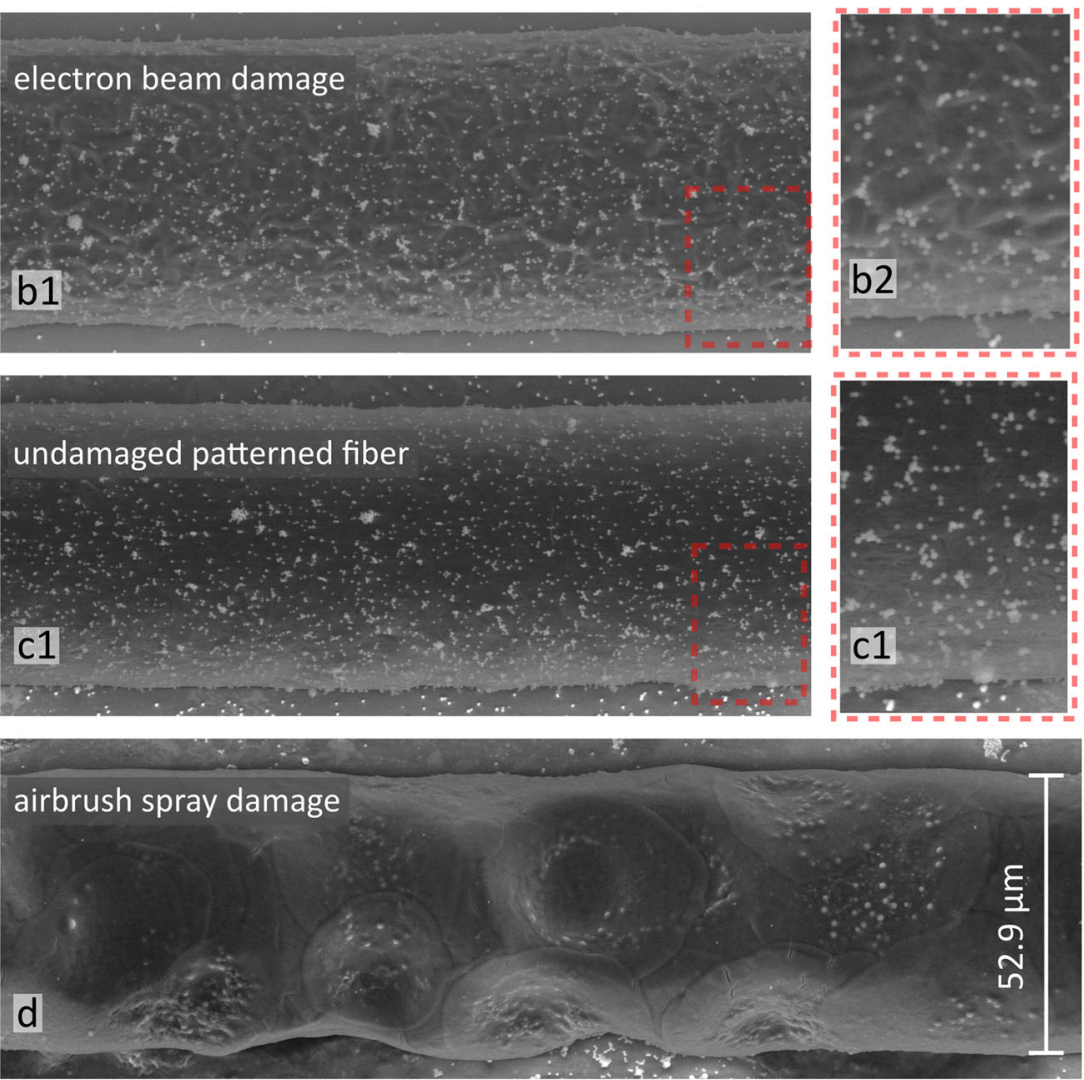
received specimen was patterned without any preparation steps. It became immediately obvious that the fiber material is very sensitive, because electron beam exposure for $\sim 1$ min during SEM imaging under mild imaging conditions (i.e., low-vacuum mode at 1 mbar and acceleration voltage of $8.5 \mathrm{kV}$ ) resulted in the specimens surface being clearly damaged (Fig. 7b). To demonstrate that the patterning technique itself did not induce any damage to the fiber, another region of the fiber, previously unexposed to the electron beam, is shown in Fig. 7c. This shows that the initial SEM scan of Fig. 7a induced the fiber surface damage seen in Fig. 7b, whereas the nanopattern application by micro-mist nebulization did not appear to induce any damage. Moreover, all attempts to delicately pattern the fiber by airbrush spraying the same NP suspension resulted in severe fiber damage, as shown in Fig. 7d, which shows (i) that the hydrogel fiber material is highly sensitive to exposure to even the mildest chemicals (i.e. the ethanol/DIwater mixture) and (ii) that during patterning using micromist nebulization the droplets of ethanol/DI-water mixture indeed evaporate and dry nanoparticles come to the surface. Both Fig. 7b and c show that the cylindrical surface of the fiber was covered well with the NPs, even at very steep side angles.

\section{Freestanding Microtensile Specimen: (EBSD Transparent Pattern on a Physically Delicate Specimen)}

Performing simultaneous electron back-scatter diffraction (EBSD) for crystallographic characterization along with DIC measurements can be of high interest, especially where it is important to understand the connection between the crystal/phase structure and the resulting microscale deformation. Examples of such multi-modal high-resolution analyses include analysis of fracture at the microstructural scale [55], change in grain orientation with deformation [55], twinning [56] or phase-transformation mediated deformation [57], or the role of complex microstructure on deformation [58, 59]. While application of DIC in such cases requires a high-density pattern, simultaneous EBSD imaging requires a pattern that is transparent to the backscatter electrons coming from the top $10 \mathrm{~nm}$ region below the surface. Furthermore, it is important to have the surface as visible as possible between the pattern speckles, e.g., in BSE or SE imaging mode, such that the strain fields can be directly superimposed on the underlying (visible) microstructure and related to directly observable surface phenomena such as slip lines and damage. Therefore, a solution such as deposition of a textured thin-film on top of the specimen does not suffice as it impedes visualizing of the specimen surface.

A test case of a freestanding microtensile polycrystalline 99.99999\% pure aluminum specimen of $5 \mu \mathrm{m}$ thickness was chosen here (see Fig. 8a). Details on the specimen are available in Ref. [58]. The freestanding nature of the specimen makes it very challenging to pattern since it cannot be brought in contact with any liquid, as the capillary force of the fluid was found to induce plastic deformation due to stiction after rinsing. The as-processed (microfabricated) specimen was patterned using $50 \mathrm{~nm}$ silica NPs for 270 mins and the patterned specimen surface is shown in Fig. 8b. The resulting nanopattern is shown in Fig. $8 \mathrm{a}$ and $\mathrm{b}$. The contrast in these SEM secondary electron images is suboptimal due to significant hydrocarbon contamination on these ( $>10$ year old) specimens, which can easily be removed by a plasma cleaning step prior to nanopattern application, however, this option was not available at the time.

Silica NPs are ideal for their EBSD and BSE transparency, as due to their lower atomic mass compared to noble metal NPs with higher atomic mass and thus shallower electron penetration depth, making it more challenging to achieve EBSD and BSE transparency, as argued in Ref. [60]. Thus, EBSD analysis can typically only be performed post-mortem after removing the DIC pattern, e.g., by rising the specimen in a chemical cleaning agent, by mechanically polishing the surface, or by performing FIB milling $[28,56]$. Here it is shown that pattern removal is not needed for EBSD analysis after micro-mist nanopattern application. To this end, after deposition, EBSD data was collected for this specimen on a FEI Serion SEM, using an acceleration voltage of $25 \mathrm{kV}$ and spot size of 5 . The EBSD scan was performed using EDAX OIM data collection software, with a $5 \times 5$ binning. As seen in the image quality (IQ) map in Fig. 8c, only at the grain boundaries the IQ is poor, which is unrelated to the NPs at the surface, while within the grains, the NPs do not reduce the $\mathrm{IQ}$, as can be seen by comparing the zoomed inset of Fig. $8 \mathrm{~b}$ with the corresponding zoomed inset of Fig. 8c. The poor IQ at the grain boundaries is caused by the fact that they are highly etched due to the microfabrication processing, creating so-called "grain boundary grooves" with steep side slopes, which results in a poor EBSD signal in those regions. A similar trend can be seen in the inverse pole figure (IPF) map, shown in the as-recorded state without any post-processing data cleaning in Fig. 8d. It is clear from the IPF map that the crystal orientation measurement quality is strongly reduced at the grain boundaries, whereas it seems completely unaffected by the NPs at the surface. There- 
Fig. 8 Pattern of $50 \mathrm{~nm}$ silica

NPs applied to a delicate freestanding microtensile specimen (polycrystalline aluminum of $5 \mu \mathrm{m}$ thickness), resulting in an EBSD-

transparent DIC nanopattern. (a) SEM image (taken with FEI

Quanta 600 FEG) of the

freestanding microtensile specimen in secondary electron mode under high vacuum, 7.5 $\mathrm{kV}$ acceleration voltage, spot size of 3, and 10-mm working distance. (b) A magnified view over the width of the specimen, marked in (a) with a red rectangle. The inset presents a further magnified view of a smaller region of interest marked by a yellow rectangle, which shows high pattern density and good pattern uniformity over the rough surface topology. (c) Image quality (IQ) map from an EBSD measurement (captured with a FEI Serion at $25 \mathrm{kV}$ and spot size of 5) of the same area as (b), showing low image quality at the grain boundaries due to grain boundary grooves with steep slopes and some variation in IQ in the grains related to the surface texture. Important, however, is that the nanoparticles have negligible detrimental effect on the image quality. (d) An inverse pole figure (IPF) map (without any post-processing or data cleaning) showing the grain orientations for the same area as the IQ map in (c). The IPF map shows the same trend as the IQ with un-indexable areas at the grain boundary grooves, but not at the nanoparticles
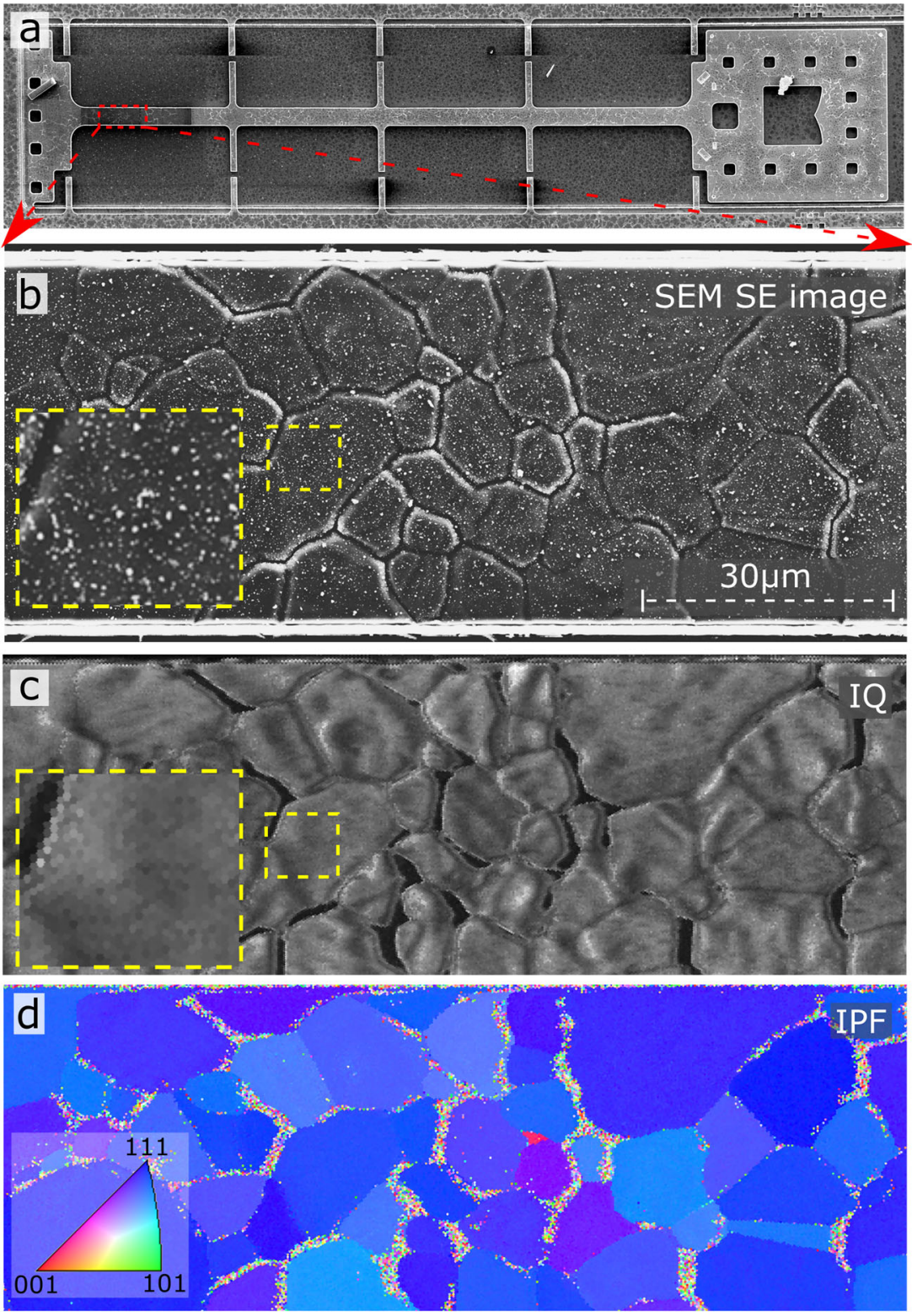

fore, these measurements demonstrate that the (high density pattern of) EBSD-transparent silica nanoparticles enables simultaneous, in-situ DIC and EBSD data collection, which is thus not limited to post-mortem analysis.

\section{Freestanding Highly Stretchable MEMS Specimen: (Topographical Pattern on an Extremely Physically Delicate Specimen)}

In the field of micro- and nano-electromechanical systems (MEMS and NEMS), material characterization is of key importance. Due to the likelihood that mechanical size-effects are active, the mechanical properties of the material cannot be assumed a priori from bulk material properties [61]. Furthermore, such size-effects typically depend on the processing conditions, therefore, either the same processing steps needs to be used for fabricating dedicated specimens or, ideally, characterization should be performed on the MEMS/NEMS structure itself. Full-field displacement data from DIC can be invaluable in such cases, especially for inhomogeneous deformation, as is the case, e.g., for strain localization due to plasticity or complex 
specimen geometries. However, due to the highly delicate nature of such free-standing nanostructures, DIC patterning becomes very challenging. Therefore, typically, the native surface pattern due to roughness, grain boundaries, voids, etc. is used as (low-quality) DIC pattern [11, 62, 63]. Here it is demonstrated that such delicate (free-standing) MEMS structures can be easily patterned with a highquality nanopattern using the micro-mist nebulization methodology.

An ultra-delicate free-standing MEMS structure, designed as highly stretchable interconnect for stretchable electronics applications, is shown in Fig. 9a. Since these specimen do not possess enough natural contrast, a nanopattern needs to be applied to enable Digital Height Correlation (DHC), which is a special form of DIC that yields three-dimensional surface displacement fields by correlating surface height profiles, here measured with an optical confocal profilometer. The microfabricated specimen is $50 \mu \mathrm{m}$ tall and micromachined from a 300- $\mathrm{nm}$ thick, sputter-deposited layer of $99.99999 \%$ Al [64]. As discussed Ref. [65], the specimens exhibit a significantly enhanced yield strength due to the likely presence of mechanical size-effects. As was recently demonstrated in Ref. [66], the displacement fields measured using DHC can be used in conjunction with an inverse characterization method named 'integrated DHC' to quantify the yield strength of the material, directly from a mechanical test on an as-processed MEMS-based specimen. Here, it is demonstrated that a micro-mist nanopattern can be applied on such ultra-delicate free-standing structures, with which it is possible to measure high-quality $3 \mathrm{D}$ displacement fields using DHC.
Fig. 9 Patterning and subsequent digital height correlation (DHC) results for an ultra-delicate freestanding stretchable electronics specimen with a height of $50 \mu \mathrm{m}$ and a thickness of $300 \mathrm{~nm}$. (a) Surface height profile of the interconnect patterned with $300 \mathrm{~nm}$ silica NPs obtained with a 100x lens of 0.9 NA and a working distance of $1 \mathrm{~mm}$ in confocal profilometry mode. The inset on the left shows a magnified view of part of the specimen, where the added 'roughness' due to the NPs is clearly visible (note that the nanopattern is significantly blurred due to the limited in-plane spatial resolution of the optical imaging system). (b, c, d) The in-plane displacement field in (b) $\mathrm{x}$ - and (c) $\mathrm{y}$ - direction and (d) the out-of-plane displacement field (in the zdirection) overlaid on an image of the freestanding interconnect

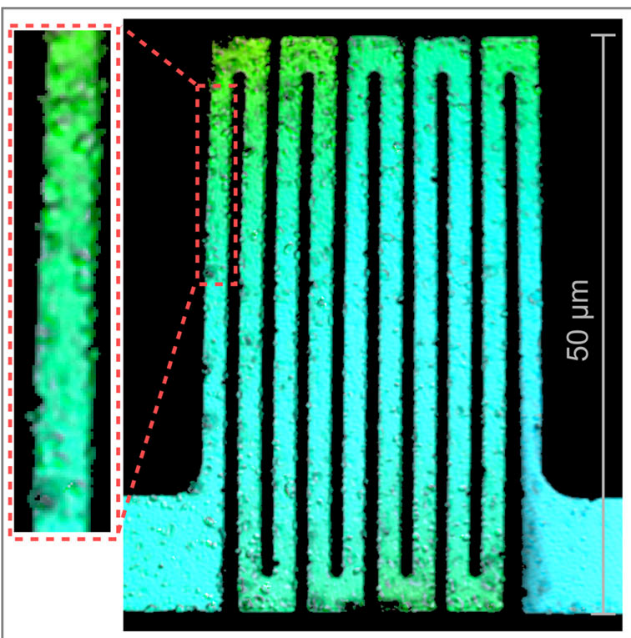

(a) patterened sample

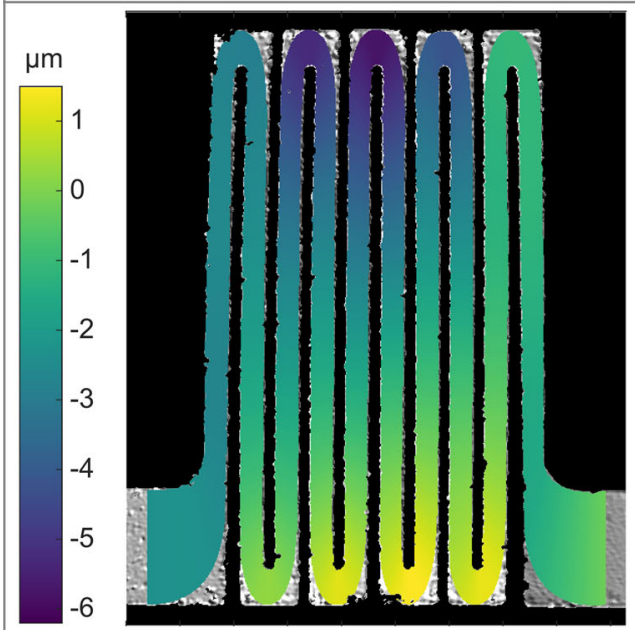

(c) $U_{y}$

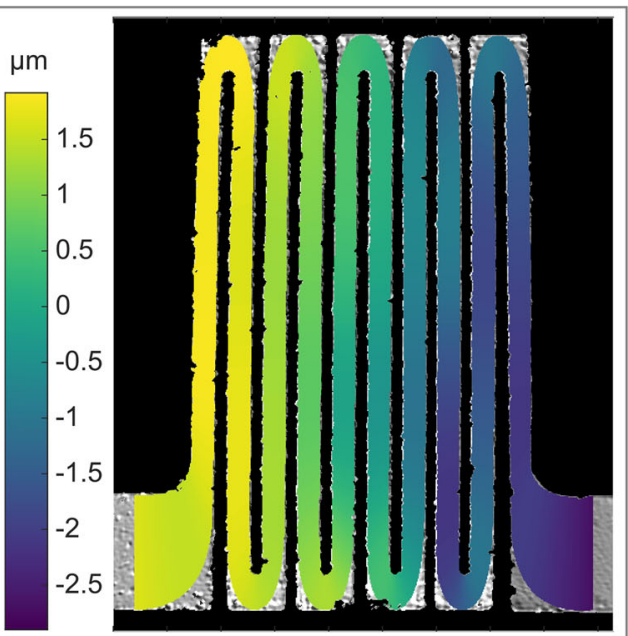

(b) $U_{x}$

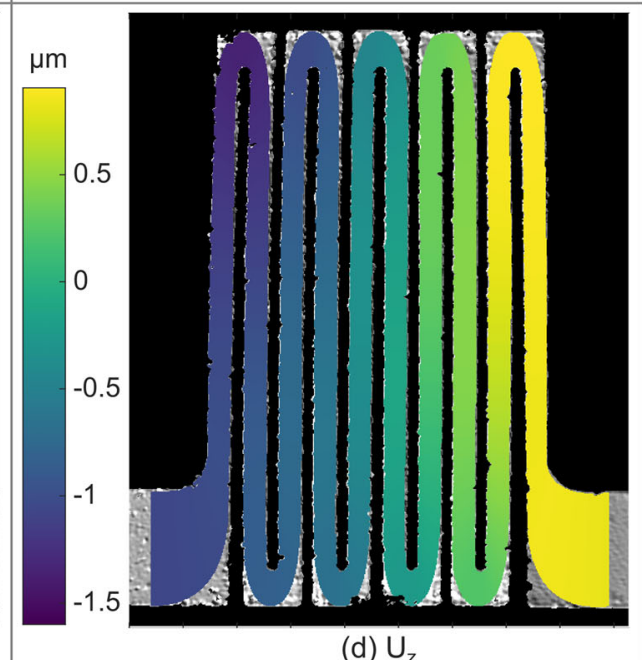


Since in regular operation, upon stretching the freestanding interconnect structure, most of the beams of the interconnect rotate by approximately $90^{\circ}$ out-of-plane thereby impeding the applicability of DHC, the following modified loading sequence was applied. The interconnects was loaded and subsequently unloaded in the out-of-plane direction multiple times, with the applied displacement being incrementally increased for each cycle. Surface height profiles were measured using a Sensofar S Neox confocal optical profilometer, using a high magnification 100x lens of $0.9 \mathrm{NA}$ and 1-mm working distance. Throughout the loading part of each cycle, the specimen beams exhibit high angles and curvatures in the out-of-plane direction, resulting in data loss over large parts of the total structure. Therefore, the surface height profiles were only captured in the unloaded configuration after each loading-unloading cycle to quantify the plastic deformation in the structure, which manifests itself as a change in curvature of the unloaded beams.

To enable high-resolution DHC based on surface height profiles, a high-quality 3D pattern is needed. This was a particularly challenging case since the in-plane spatial resolution (due to the diffraction-limited optical system of the optical profilometer) is estimated to be $\sim 250 \mathrm{~nm}$ thus it was important to use particles larger than this value, however, they should also be much smaller than the width of the beams, which is only $2 \mu \mathrm{m}$. Therefore, the choice of pattern size was severely constrained. Here, the choice was made to apply a pattern of $300 \mathrm{~nm}$ silica particles, even though this pattern size is very close to spatial resolution. To this end, the original suspension was diluted by 1:9000 and the specimen was patterned for $3 \mathrm{hrs}$. As seen in Fig. 9a, the density of the pattern is not as high as in previous examples, which is mainly due to the fact that the pattern could not be optimized due to scarcity of available highly-stretchable interconnect specimens. Yet, the nanopattern does fulfill the requirement of having quite a sufficient number of particles over the specimen length, which is needed for the hereemployed global DHC algorithm in which a mesh of NonUniform Rational B-Splines (NURBS) is used as kinematic regularization of the 3D displacement field. The specimen was meshed with four elements over the length and one element over each beam element, with $2^{\text {nd }}$ order shape functions in the beam length direction and $0^{\text {th }}$ order shape function on the beam width direction. Further details on the NURBS based DIC algorithm can be found in Refs. [67, 68].

Using DHC, the three-dimensional displacement fields of the stretchable interconnect specimen could be successfully mapped in the in-plane and out-of-plane directions (see
Fig. 9b-d). This shows that it is possible to apply a 3D nanopattern using the micro-mist nebulization methodology on even the most delicate free-standing MEMS-based microstructures, and that such patterns are effective in providing the $3 \mathrm{D}$ surface displacement field (when an appropriate (global) DHC algorithm is employed).

\section{Concluding Remarks}

Herein, a new technique for patterning the otherwise challenging small-scale fragile specimens is presented, to enable DIC-based micromechanical analysis of such structures. The technique consists of generating a wellcontrolled mist of a (water/ethanol) volatile suspension containing the nanoparticles, while the mist evaporates before reaching the specimen, thereby resulting ideally in single particles landing individually on the specimen surface. The technique circumvents the numerous issues with application of NPs directly from a volatile suspension, using the so-called 'drop casting' method. A number of examples of patterning of delicate specimens have been presented that demonstrate the feasibility and strengths of the method. Silica particle from $1 \mu \mathrm{m}$ down to $50 \mathrm{~nm}$ in diameter have been applied successfully yielding a high quality pattern with high density, homogeneous distribution and good contrast. It is expected that it is possible to deposit smaller particles as well, although this has not yet been tested. There are a number of advantages of this technique, namely:

\section{Dry, chemically inert, non-contact process}

A key advantage of this technique is that it is inherently dry in nature, which is of essence when dealing with small-scale freestanding structures such as the microtensile specimen or the $300 \mathrm{~nm}$ thick stretchable interconnect patterned here, for which contact with liquids can easily lead to damage. Furthermore, the chemically inert nature of the used airflow means that chemically fragile or sensitive specimens, such as the here-tested hydrogel fibers or other biological specimens, can be easily patterned.

2. Near-room temperature patterning process

The deposition is performed at a low temperature of $\sim 37^{\circ} \mathrm{C}$. For applications that might require operation at even lower temperatures, the heating tube temperature in conjunction with the nozzle-to-specimen distance and the flow-rate can easily be varied and optimized.

3. Specimen material and topography independent deposition 
This technique is effectively independent of the specimen surface properties and can be used to pattern specimens with varying specimen composition, as demonstrated by patterning of a multilayered LED cross-section specimen. Similarly, specimens with varying surface topography can be patterned, as was the case for cylindrically-shaped hydrogel fibers tested here.

\section{Pattern scalability}

It has been shown that the technique is scalable in the range from $1 \mu \mathrm{m}$ and lower speckle sizes, which is the ideal regime for micromechanical testing. The only parameter that needs to be optimized with the change in particle size is the concentration of the suspension. Note that, for scales larger than $1 \mu \mathrm{m}$, applying microspheres or ink based spray using an airbrush is often a good option, as already reported in literature [14].

5. Low costs setup and pattern application Finally, an advantage is the relatively low setup and operation costs. For instance, all setup parts together costed approximately $<\$ 1000$, while the microspheres particles are also relatively low priced. For instance, the 500 $\mathrm{nm}$ silica particles were approximately $\$ 6$ per deposited specimen.

A limitation of the technique is that very high pattern density, such as reported for thin-film remodeling based techniques [14, 16, 20], might not be possible. The density of the pattern seems to saturate with an average particle to particle spacing (center to center) of 4-6 times the particle diameter. A solution for cases where very high density is required can be to use smaller particles sizes relative to the field of view. However it should be noted that for accurate DIC application, each speckle (NP) should span over at least 3 pixels as discussed in Ref. [69], to avoid aliasing errors. For decreasing the deposition time and increasing the maximum density possible with this technique, a few possible improvements, which could not be evaluated in this work, are provided as suggestions here.

Firstly, a so-called 'Allihn reflux' condenser can be added instead of the glass inlet adapter (Fig. 1 [C1]) to condense and separate the ethanol and water vapor from the flow that reaches the specimen surface. With minimal liquid vapor in the flow, it might be possible to move the specimen closer to the nozzle than the current $7.5 \mathrm{~cm}$ specimen-tonozzle optimized distance. A smaller specimen-to-nozzle distance should enable a higher concentration of NPs landing over the specimen surface, albeit over a smaller diameter, approximately equal to the nozzle diameter. Furthermore, that would enable the deposition to take place at room temperature even at very small specimen-to-nozzle distances.

Secondly, a possible reason for the saturation of pattern density (once the spacing between adjacent particles reaches 4-6 times the particle diameter) might be linked to the charge on the NPs. This charge originally helps NPs disperse well in the suspension by generating inter-NP repulsion. It is suspected that once a large number of these charged NPs have been deposited on the specimen surface they repel the in-coming charged NPs to land close to them on the specimen surface. To eliminate this charge on the nebulized NPs a (low-cost and readily commercially available) gas ionizer ('static eliminator') could be added at the nozzle of the heated copper tubing (Fig. 1 [C2]).

\section{Appendix}

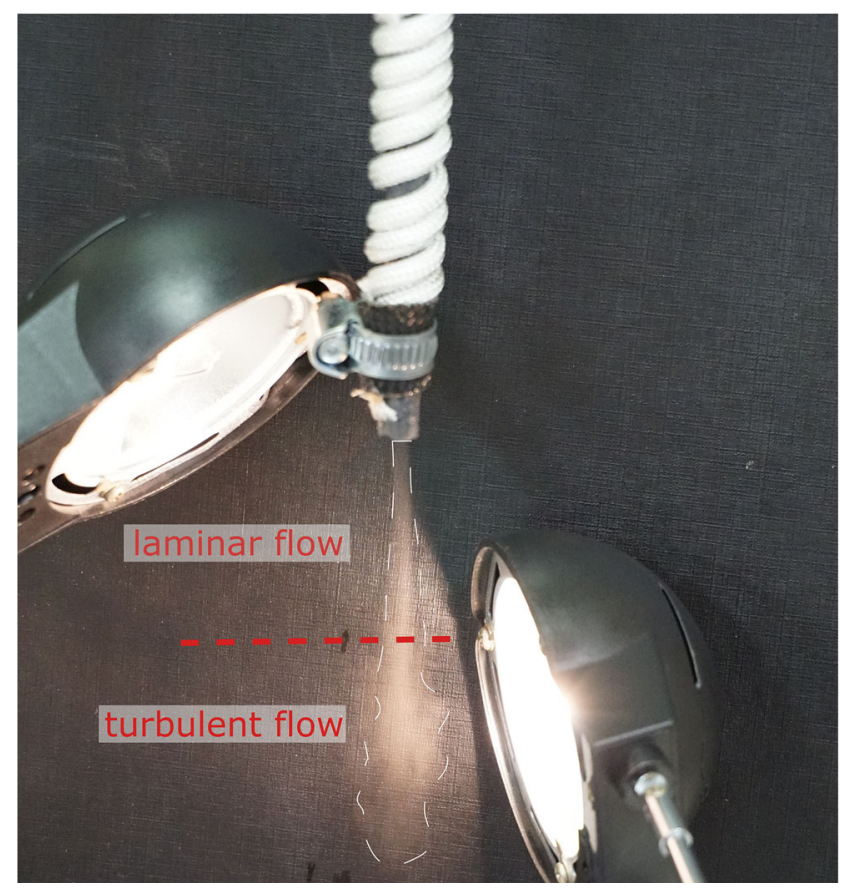

Fig. 10 Photograph of the flow of the nebulized mist from the nozzle, showing a laminar and turbulent flow regime. The flow of nebulized mixture was visualized, as a faint translucent flow, by turning the rope heater off while illuminated the flow from the side, a configuration that enables direct optimization of the specimen-to-nozzle distance in order to position the specimen in the center of the turbulent flow regime 
Table 2 The nanoparticles that were tested in this work, together with the corresponding (optimized) patterning parameters

\begin{tabular}{|c|c|c|c|c|c|}
\hline $\begin{array}{l}\text { particle size } \\
(\mathrm{nm})\end{array}$ & NP material & $\begin{array}{l}\text { original } \\
\text { suspension } \\
\text { concentration } \\
(\mathrm{mg} / \mathrm{ml})\end{array}$ & $\begin{array}{l}\text { original } \\
\text { suspension } \\
\text { dilution in solvent } \\
\text { (vol:vol) }\end{array}$ & $\begin{array}{l}\text { flow rate } \\
\text { (LPM) }\end{array}$ & $\begin{array}{l}\text { specimen } \\
\text { to nozzle } \\
\text { height } \\
(\mathrm{cm})\end{array}$ \\
\hline 50 & silica (plain) & 25 & $1: 40000$ & 3 & 7.5 \\
\hline 200 & polystyrene (plain) & 25 & $1: 6000$ & 3 & 7.5 \\
\hline 500 & silica (plain) & 50 & $1: 4000$ & 3 & 7.5 \\
\hline 1000 & polystyrene (plain) & 50 & $1: 100$ & 3 & 7.5 \\
\hline
\end{tabular}

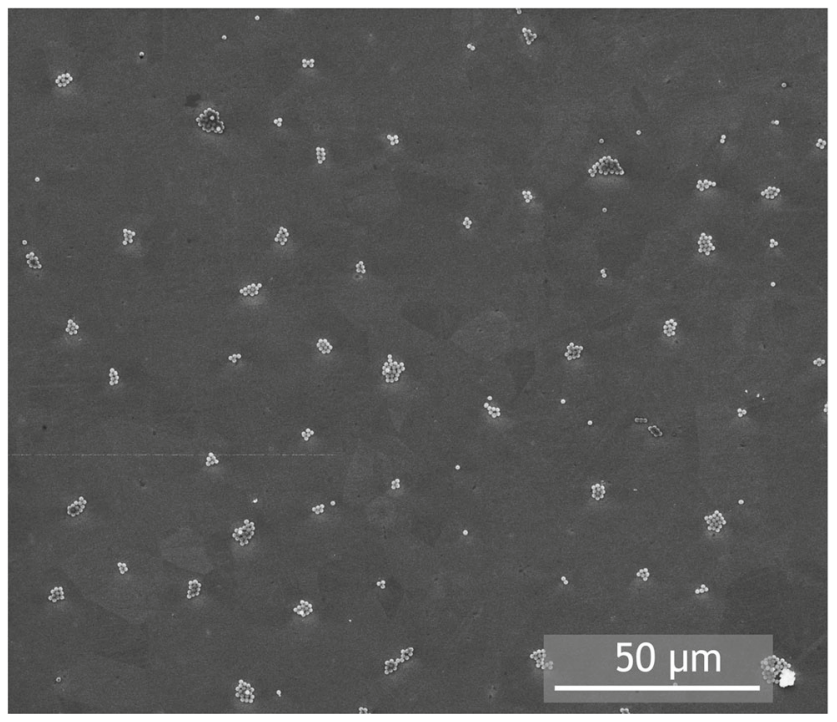

Fig. 11 Example of deposition in the laminar regime, resulting in planar aggregation on the specimen. The specimen was deposited at a specimen-to-nozzle distance of $4 \mathrm{~cm}$, instead of the optimized 7.5 $\mathrm{cm}$ distance, and was patterned for 10 mins with $1 \mu \mathrm{m}$ polystyrene particles. The specimen was imaged with a FEI Quanta 600 FEG SEM under high vacuum in secondary electron imaging mode, at an acceleration voltage of $30 \mathrm{kV}$, spot size of 3 , and working distance of $10 \mathrm{~mm}$

Supplementary Information The online version contains supplementary material available at https://doi.org/10.1007/s11340-020-00686-2.

Acknowledgments The authors would like to acknowledge the kind support of Sandra van de Looij - Kleinendorst for the digital height correlation example, Varun Shah for performing EBSD scans, Lucien Cleven for his support in fabricating the setup, Lambert Bergers, Andre Ruybalid and Niels Vonk for providing test specimens, Weijia Zhu, Nick Verschuur and Inge van der Kuil for assistance to initial experiments, and Marc van Maris for general technical support.

\section{Declarations}

The authors state that regarding the research and writing of the manuscript, there are no conflicts of interest and that all the authors consent to the content of the manuscript. This work was supported by the VIDI personal grant of J.P.M.H. (project number 12966) by the Netherlands Organization for Scientific Research (NWO).
Open Access This article is licensed under a Creative Commons Attribution 4.0 International License, which permits use, sharing, adaptation, distribution and reproduction in any medium or format, as long as you give appropriate credit to the original author(s) and the source, provide a link to the Creative Commons licence, and indicate if changes were made. The images or other third party material in this article are included in the article's Creative Commons licence, unless indicated otherwise in a credit line to the material. If material is not included in the article's Creative Commons licence and your intended use is not permitted by statutory regulation or exceeds the permitted use, you will need to obtain permission directly from the copyright holder. To view a copy of this licence, visit http:// creativecommonshorg/licenses/by/4.0/.

\section{References}

1. Schreier H, Orteu JJ, Sutton MA (2009) Image correlation for shape, motion and deformation measurements, 1st edn. Springer US, Boston

2. Lava P, Coppieters S, Van Hecke R, Van Houtte P, Debruyne D (2014) Digital image correlation in the classroom: determining stress concentration factors with webcams. Exp Tech 38(4): $72-80$

3. Wang X, Pan Z, Fan F, Wang J, Liu Y, Mao SX, Zhu T, Xia $S$ (2015) Nanoscale deformation analysis with high-resolution transmission electron microscopy and digital image correlation. Journal of Applied Mechanics 82(12):121001

4. Yoneyama S, Kitagawa A (2007) Bridge deflection measurement using digital image correlation. Experimental Techniques (February) 53:34-40

5. Grégoire D, Loh O, Juster A, Espinosa HD (2011) In-situ AFM experiments with discontinuous DIC applied to damage identification in biomaterials. Exp Mech 51(4):591-607

6. Li X, Xu W, Sutton MA, Mello M (2007) In situ nanoscale inplane deformation studies of ultrathin polymeric films during tensile deformation using atomic force microscopy and digital image correlation techniques. IEEE Transactions On Nanotechnology 6(1):4-12

7. Jin H, Lu WY, Korellis J (2008) Micro-scale deformation measurement using the digital image correlation technique and scanning electron microscope imaging. The Journal of Strain Analysis for Engineering Design 43(8):719-728

8. Kammers AD, Daly S (2013) Digital image correlation under scanning electron microscopy: methodology and validation. Exp Mech 53(9):1743-1761

9. Lagattu F, Bridier F, Villechaise P, Brillaud J (2006) In-plane strain measurements on a microscopic scale by coupling digital 
image correlation and an in situ SEM technique. Mater Charact 56(1):10-18

10. Sutton MA, Li N, Garcia D, Cornille N, Orteu JJ, McNeill SR, Schreier HW, Li X (2006) Metrology in a scanning electron microscope: theoretical developments and experimental validation. Meas Sci Technol 17(10):2613-2622

11. Bergers LIJC, Hoefnagels JPM, Geers MGD (2014) Characterization of time-dependent anelastic microbeam bending mechanics. Journal of Physics D: Applied Physics 47(35):355306

12. Sun Y, Pang JHL, Wong CK, Su F (2005) Finite element formulation for a digital image correlation method. Appl Opt 44(34):7357

13. Kammers AD, Daly S (2011) Small-scale patterning methods for digital image correlation under scanning electron microscopy. Measurement Science and Technology 22(12):125501

14. Dong YL, Pan B (2017) A review of speckle pattern fabrication and assessment for digital image correlation. Exp Mech 57(8):1161-1181

15. Luo Y, Ruff J, Ray R, Gu Y, Ploehn HJ, Scrivens WA (2005) Vapor-assisted remodeling of thin gold films. Chem Mater 17(20):5014-5023

16. Scrivens WA, Luo Y, Sutton MA, Collette SA, Myrick ML, Miney P, Colavita PE, Reynolds AP, Li X (2007) Development of patterns for digital image correlation measurements at reduced length scales. Exp Mech 47(1):63-77

17. Di Gioacchino F, Quinta da Fonseca J (2013) Plastic strain mapping with sub-micron resolution using digital image correlation. Exp Mech 53(5):743-754

18. Edwards TEJ, Di Gioacchino F, Springbett HP, Oliver RA, Clegg WJ (2017) Stable speckle patterns for nano-scale strain mapping up to $700^{\circ} \mathrm{c}$. Exp Mech 57(9):1469-1482

19. Montgomery CB, Koohbor B, Sottos NR (2019) A robust patterning technique for electron microscopy-based digital image correlation at sub-micron resolutions. Exp Mech 59(7):1063-1073

20. Hoefnagels JPM, van Maris MPFHL, Vermeij T (2019) Onestep deposition of nano-to-micron-scalable, high-quality digital image correlation patterns for high-strain in-situ multi-microscopy testing. Strain 55(6):e12330

21. Jonnalagadda KN, Chasiotis I, Yagnamurthy S, Lambros J, Pulskamp J, Polcawich R, Dubey M (2010) Experimental investigation of strain rate dependence of nanocrystalline Pt films. Exp Mech 50(1):25-35

22. Jonnalagadda K, Karanjgaokar N, Chasiotis I, Chee J, Peroulis D (2010) Strain rate sensitivity of nanocrystalline au films at room temperature. Acta Mater 58(14):4674-4684

23. Das D, Power B, Martin JP, Polcawich RG, Chasiotis I (2016) Role of oxide seed layer in plastic response of epitaxially grown textured metal films. Acta Mater 112:390-402

24. Lughi V (2016) Surface energy and chemical potential at nanoscale. Springer, Netherlands, Dordrecht, pp 3907-3917

25. Shrestha S, Wang B, Dutta P (2020) Nanoparticle processing: understanding and controlling aggregation. Adv Colloid Interf Sci 279:102162

26. He YT, Wan J, Tokunaga T (2008) Kinetic stability of hematite nanoparticles: the effect of particle sizes. J Nanoparticle Res 10(2):321-332

27. Xu L, Liang HW, Yang Y, Yu SH (2018) Stability and reactivity: positive and negative aspects for nanoparticle processing. Chem Rev 118(7):3209-3250

28. Kammers AD, Daly S (2013) Self-assembled nanoparticle surface patterning for improved digital image correlation in a scanning electron microscope. Exp Mech 53(8):1333-1341

29. Adair JH, Suvaci E, Sindel J (2001) Surface and colloid chemistry, pp 8996-9006. No. v.10 in Encyclopedia of Materials: Science and Technology, Elsevier
30. Githens A, Daly S (2017) Patterning corrosion-susceptible metallic alloys for digital image correlation in a scanning electron microscope. Strain 53(1):e12215

31. Guo SM, Sutton MA, Li N, Li XD, Wang LW, Rajan S (2017) Measurement of local thermal deformations in heterogeneous microstructures via SEM imaging with digital image correlation. Exp Mech 57(1):41-56

32. Winiarski B, Schajer GS, Withers PJ (2012) Surface decoration for improving the accuracy of displacement measurements by digital image correlation in SEM. Exp Mech 52(7):793-804

33. Ronghua Z, Huimin X, Yunfei X, Liang W, YanJie L (2015) Fabrication of speckle patterns by focused ion beam deposition and its application to micro-scale residual stress measurement. Measurement Science and Technology 26(9):095601

34. Guery A, Latourte F, Hild F, Roux S (2013) Characterization of SEM speckle pattern marking and imaging distortion by digital image correlation. Measurement Science and Technology 25(1):015401

35. Berfield TA, Patel JK, Shimmin RG, Braun PV, Lambros J, Sottos NR (2007) Micro- and nanoscale deformation measurement of surface and internal planes via digital image correlation. Exp Mech 47(1):51-62

36. Bhardwaj R, Fang X, Somasundaran P, Attinger D (2010) Selfassembly of colloidal particles from evaporating droplets: role of DLVO interactions and proposition of a phase diagram. Langmuir 26(11):7833-7842

37. Tsai SC, Song YL, Tsai CS, Yang CC, Chiu WY, Lin HM (2004) Ultrasonic spray pyrolysis for nanoparticles synthesis. J Mater Sci 39(11):3647-3657

38. Harvey CJ, O'Doherty MJ, Page CJ, Thomas SH, Nunan TO, Treacher DF (1997) Comparison of jet and ultrasonic nebulizer pulmonary aerosol deposition during mechanical ventilation. Eur Respir J 10(4):905-909

39. Yeo LY, Friend JR, McIntosh MP, Meeusen ENT, Morton DAV (2010) Ultrasonic nebulization platforms for pulmonary drug delivery. Expert Opinion on Drug Delivery 7(6):663-679

40. Kim DY, Lee CH, Park SJ (1996) Preparation of zirconia thin films by metalorganic chemical vapor deposition using ultrasonic nebulization. J Mater Res 11(10):2583-2587

41. Kim IT, Lee CH, Park SJ (1994) Preparation of BaTiO 3 thin films by metalorganic chemical vapor deposition using ultrasonic spraying. Jpn J Appl Phys 33(Part 1, No. 9B):5125-5128

42. Singh P, Kumar A, Deepak, Kaur D (2007) Growth and characterization of $\mathrm{ZnO}$ nanocrystalline thin films and nanopowder via low-cost ultrasonic spray pyrolysis. J Cryst Growth 306(2):303310

43. Janaćković DJ, Jokanović V, Kostić-Gvozdenović LJ, Zec S, Uskoković D (1997) Synthesis and formation mechanism of submicrometre spherical cordierite powders by ultrasonic spray pyrolysis. J Mater Sci 32(1):163-168

44. Song YL, Tsai SC, Chen CY, Tseng TK, Tsai CS, Chen JW, Yao YD (2005) Ultrasonic spray pyrolysis for synthesis of spherical zirconia particles. J Am Ceram Soc 87(10):1864-1871

45. Rodes C, Smith T, Crouse R, Ramachandran G (1990) Measurements of the size distribution of aerosols produced by ultrasonic humidification. Aerosol Sci Technol 13(2):220-229

46. Belda Maximino R (2009) Surface tension and density of binary mixtures of monoalcohols, water and acetonitrile: equation of correlation of the surface tension. Phys Chem Liq 47(5):475-486

47. Biswas S (2018) Physics of turbulent jet ignition. Springer Theses, Springer International Publishing, Cham

48. Wu DJ, Vonk NH, Lamers BA, Castilho M, Malda J, Hoefnagels JPM, Dankers PY (2020) Anisotropic hygro-expansion in hydrogel fibers owing to uniting 3D electrowriting and supramolecular polymer assembly. Eur Polym J 141:110099 
49. Jamal M, Kadam SS, Xiao R, Jivan F, Onn TM, Fernandes R, Nguyen TD, Gracias DH (2013) Bio-origami hydrogel scaffolds composed of photocrosslinked peg bilayers. Advanced Healthcare Materials 2(8):1142-1150

50. Sydney Gladman A, Matsumoto EA, Nuzzo RG, Mahadevan L, Lewis JA (2016) Biomimetic 4D printing. Nat Mater 15(4):413418

51. Han K, Ciccotti M, Roux S (2010) Measuring nanoscale stress intensity factors with an atomic force microscope. EPL (Europhysics Letters) 89(6):66003

52. Neggers J, Hoefnagels JPM, Hild F, Roux S, Geers MGD (2014) Direct stress-strain measurements from bulged membranes using topography image correlation. Exp Mech 54(5):717-727

53. van Beeck J, Neggers J, Schreurs PJG, Hoefnagels JPM, Geers MGD (2014) Quantification of three-dimensional surface deformation using global digital image correlation. Exp Mech 54(4):557-570

54. Vonk NH, Verschuur NAM, Peerlings RHJ, Geers MGD, Hoefnagels JPM (2020) Robust and precise identification of the hygro-expansion of single fibers: a full-field fiber topography correlation approach. Cellulose 27(12):6777-6792

55. Carroll JD, Abuzaid W, Lambros J, Sehitoglu H (2013) High resolution digital image correlation measurements of strain accumulation in fatigue crack growth. Int J Fatigue 57:140-150

56. Edwards TEJ, Di Gioacchino F, Muñoz-Moreno R, Clegg WJ (2016) Deformation of lamellar TiAl alloys by longitudinal twinning. Scr Mater 118:46-50

57. Holzweissig MJ, Kanagarajah P, Maier HJ (2014) Digital image correlation at high temperatures for fatigue and phase transformation studies. Journal of Strain Analysis for Engineering Design 49(4):204-211

58. Bergers LIJC, Hoefnagels JPM, Geers MGD (2014) On-wafer time-dependent high reproducibility nano-force tensile testing. Journal of Physics D: Applied Physics 47(49):495306

59. Zhao C, Stewart D, Jiang J, Dunne FPE (2018) A comparative assessment of iron and cobalt-based hard-facing alloy deformation using HR-EBSD and HR-DIC. Acta Mater 159:173-186
60. Yan D, Tasan CC, Raabe D (2015) High resolution in situ mapping of microstrain and microstructure evolution reveals damage resistance criteria in dual phase steels. Acta Mater 96:399-409

61. Espinosa HD, Prorok B, Fischer M (2003) A methodology for determining mechanical properties of freestanding thin films and MEMS materials. Journal of the Mechanics and Physics of Solids 51(1):47-67

62. Cho SW, Chasiotis I (2007) Elastic properties and representative volume element of polycrystalline silicon for MEMS. Exp Mech 47(1):37-49

63. Cho SW, Jonnalagadda K, Chasiotis I (2007) Mode I and mixed mode fracture of polysilicon for MEMS. Fatigue \& Fracture of Engineering Materials and Structures 30(1):21-31

64. Savov A, Joshi S, Shafqat S, Hoefnagels JPM, Louwerse M, Stoute R, Dekker R (2018) A platform for mechano(-electrical) characterization of free-standing micron-sized structures and interconnects. Micromachines 9(1):39

65. Shafqat S, Hoefnagels JPM, Savov A, Joshi S, Dekker R, Geers MGD (2017) Ultra-stretchable interconnects for high-density stretchable electronics. Micromachines 8(9):277

66. Kleinendorst SM, Shafqat S, Geers MGD, Hoefnagels JPM (2020) Parameter identification of micron-sized freestanding stretchable electronic interconnects using Integrated Digital Height Correlation. Measurement Science and Technology. Accepted for publicaton

67. Li B, Peco C, Millán D, Arias I, Arroyo M (2015) Phase-field modeling and simulation of fracture in brittle materials with strongly anisotropic surface energy. Int J Numer Methods Eng 102(3-4):711-727

68. Kleinendorst SM, Hoefnagels JPM, Fleerakkers RC, van Maris MPFHL, Cattarinuzzi E, Verhoosel CV, Geers MGD (2016) Adaptive isogeometric digital height correlation: application to stretchable electronics. Strain 52(4):336-354

69. Reu P (2014) All about speckles: aliasing. Exp Tech 38(5):1-3

Publisher's Note Springer Nature remains neutral with regard to jurisdictional claims in published maps and institutional affiliations. 